\title{
Spurious weather effects
}

\author{
Jo Thori Lind*
}

Thursday $9^{\text {th }}$ August, 2018

\begin{abstract}
Rainfall is exogenous to human actions and hence popular as an exogenous source of variation. But it is also spatially correlated. This can generate spurious relationships between rainfall and other spatially correlated outcomes. As an illustration, rainfall on almost any day of the year has seemingly high predictive power of electoral turnout in Norwegian municipalities. In Monte Carlo analyses, I find that standard tests reject true null hypotheses in as much as 99 percent of cases. Standard approaches to estimating consistent standard errors do not solve the problem. Instead, I suggest controlling for spatial and spatio-temporal trends using multi-dimensional polynomials.
\end{abstract}

Keywords: Rainfall, electoral turnout, spurious relationship, spatial correlation

JEL Codes: C13, C14, C21, D72

Funding: This work was supported by the Research Council of Norway through its Centres of Excellence funding scheme, project number 179552.

*Department of Economics, University of Oslo, PB 1095 Blindern, 0317 Oslo, Norway. Email: j.t.lind@econ.uio.no. Tel. (+47) 22844027. 


\section{INTRODUCTION}

Both human behavior and economic outcomes, such as individual effort and agricultural productivity, depend on weather conditions. Weather phenomena, moreover, can generally be seen as exogenous to human behavior. The effect of rainfall on the demand for umbrellas, known from numerous introductions to decisions under uncertainty, is only one example. In empirical economic research, truly exogenous variables are sought after as sources of exogenous variation to provide causal inference. Going at least back to Koopmans (1949), economists have been using rainfall as an exogenous shock. In recent years, the strategy has become increasingly popular.

Few suspect that human actions affect the weather in the short run, ${ }^{1}$ and the weather has a potential impact on a number of outcomes. But by its very nature, rainfall is spatially and temporally correlated. If it is raining in one location, the likelihood of rain in nearby areas is high. Autocorrelated explanatory variables are not usually considered problematic. I show, however, that this induces a danger of spurious correlations when omitted variables also display spatial dependency, i.e. that magnitudes in nearby locations tend to be positively correlated.

When rainfall is included in a regression with spatially dependent omitted variables, rainfall is going to appear relevant even when it is not. The problem is that omitted variables problems are exacerbated in the presence of spatial dependency. Unlike ordinary omitted variables problems, however, we face an omitted variable whose true effect is random. In both cross sectional and panel data, it is common to observe spatial patterns in most outcomes, probably including unobserved omitted variables. As there is spatial dependency in rainfall as well, I show that although rainfall is unrelated to all variables of interest, it is going to correlate with other spatially dependent variables. In panel data, where spatial trends can be controlled by fixed effects, the same problem arises if there are combined temporally and spatially trends in outcomes of interest. As shown by Granger et al. (2001) and Kim et al. (2004), a similar effect can actually arise in a pure time series setting too. This is an effect leading to biased and inconsistently estimated parameters. Hence correcting standard errors for spatial clustering at geographic entities (Moulton, 1986) or following e.g. Conley's (1999) approach, does little to solve the problem. ${ }^{2}$

To illustrate the magnitude of the problem, consider the relationship between electoral turnout 
and rainfall. There may be good reasons to expect a relationship between turnout and rainfall on election day. But rainfall on other days, with a possible exception of a few days prior to the election, should not have any impact. Using data from Norwegian municipal elections and daily rainfall data in the window from 600 days before to 600 days after the election, I find that rainfall on almost every day has an impact on electoral turnout. ${ }^{3}$ As the regressions include both municipality and year dummies, explanations such as the probability of rain can not explain the findings.

In these analyses we should only expect to find significant results due to the expected Type I errors determined by the level of significance. That is not the case. Rather, a $5 \%$ significance test reject the hypothesis of no effect of precipitation in $70.8 \%$ of the cases. The estimated t-values are shown in Figure 1. Although the distribution is symmetric around zero, the variance is much higher than the expected level of unity. Moreover, the distribution is not normal, as the tails are lighter than the normal kurtosis. Clustering standard errors at the regional, rather than the local level, improves the situation somewhat. But still a $5 \%$ test rejects in $46.4 \%$ of cases, and this level of clustering is more conservative than what is used in most applied studies. The phenomenon can not be explained by heavy tailed distributions ${ }^{4}$ or geographically seasonal patterns in precipitation. ${ }^{5}$ If this phenomenon was unique to the effect of rainfall on electoral turnout, it would be a narrow problem. However, the problem applies potentially to all spatially correlated outcome variables ${ }^{6}$ as well as explanatory variables exhibiting patterns similar to rainfall. ${ }^{7}$

[Figure 1 about here.]

As I argue below, the reason for this odd behavior is the presence of spatio-temporal tends in the dependent variable: turnout in the eastern part of the country has decreased relative to national averages whereas it has increased in relative terms in the western part. The underlying explanation is probably differential development of macro-regional common factors. In some ways, this mimics the intricate spatial patterns detected in earnings data by Barrios et al. (2012), but here also with a temporal component. In a stylized model with an omitted spatially correlated variable, I show theoretically that OLS estimates are inconsistent with almost surely diverging point estimates and t-statistics. Using Monte Carlo simulations, I further show that the test of 
the irrelevance of the irrelevant variable is vastly over-rejected. This holds both with large sample sizes, with several independent clusters of spatially dependent variables, using cross-sectional and panel data, as well as several specifications of the omitted trend including spatial AR processes. Also, the simulations indicate that neither ordinary clustered standard errors nor Conley (1999) standard errors solve the problem.

My suggested solution to the problem is to control for the trend using orthogonal polynomials. ${ }^{8}$ In the cross sectional spatial case, such a trend would be a polynomial in geographical coordinates. In the case of panel data, we need a time trend whose slope varies geographically, so the slope of the trend is modeled by a similar polynomial in geographical coordinates. Although any polynomial can be used in theory, sequences of orthogonal polynomials have good numerical stability. In the current study, I focus on tensor products of Legendre polynomials, which seem to perform well.

There are a few papers scrutinizing the validity of rainfall as an exogenous source of variation. Sarsons (2015) look at the relationship between rainfall and conflict in India, where rainfall typically is believed to be an instrument for income. However, she finds strong effects of rainfall both in rain-fed and dam-fed regions, possibly invalidating this identification.

Methodologically, the present paper is also closely related to the work of Bertrand et al. (2004). They show that differences in differences estimation tends to find effects of placebo "reforms" on female wages. In one way, the present paper is a converse to their study as they focus on outcomes with spatial patterns (wages) whereas I focus on explanatory variables with spatial patterns. The study by Barrios et al. (2012) also indicate that failing to accounting for spatial dependency may severely bias the results, but they also focus on standard errors.

The paper is also related to literature on spurious regressions in time series. It is well known that the presence of non-stationary variables in regressions analyses can lead to spurious regression (Granger \& Newbold, 1974; Phillips, 1986). A less well known result is that this also holds for a wide range of processes, including autocorrelated stationary processes (Granger et al., 2001; Kim et al., 2004) - see Ventosa-Santaulària (2009) for a review. The problems I discuss are very similar, but in the spatial domain.

Also, my suggested solution to estimate spatial or spatio-temporal trends relates to the litera- 
ture on estimating time trends (Sims et al., 1990). As this concerns units in space, it also relates to the massive literature on spatial statistics ${ }^{9}$ and the more modest literature on spatial econometrics. ${ }^{10}$ The literature on spatio-temporal statistics has a strong focus on space-time autoregressive moving average (STARMA) type models (Cliff et al., 1975; Pfeifer \& Deutsch, 1980), characterized by linear dependence lagged in both space and time. The literature on estimating models with spatially dependent error terms is particularly relevant (Kelejian \& Prucha, 1999; Chudik et al., 2011; Pesaran \& Tosetti, 2011). Such models can also be extended to regression frameworks with spatial autoregressive distributed lags models (Elhorst, 2001). Although these models may be suited to handle the problem at hand, their main problem is that they are difficult to identify and estimate by themselves. When we also want to add panel data features, clustered standard errors, instrumental variables or discontinuity designs, they become intractable and not useful for practical applications. Hence, I have chosen to rely on a simpler approach.

My suggested solution is to allow for a spatially varying time trend. This relates to the literature on varying coefficients (Hastie \& Tibshirani, 1993) and particularly spatially varying coefficients (Gelfand et al., 2003). Specifically, Hoover et al. (1998) and Huang et al. (2002) estimate varying coefficients models where they model the coefficients by regularized basis functions as I suggest (albeit using B-splines rather than polynomial bases). ${ }^{11}$ However, they consider coefficients varying in time, not in space. To the best of my knowledge, the only spatial application of the methodology is Zhu et al. (2014) who study MRI images.

\section{THE PROBLEM}

\subsection{Rainfall regressions}

The use of meteorological data in empirical analyses has skyrocketed in recent years. ${ }^{12}$ Some of these take worries of spurious correlations into account by running placebo studies, but this is not yet widespread. To both study the use of rainfall in applied empirical economics and see how potential issues of spurious relationships are handled, I surveyed all articles published in three top economics journals in the period 2000-2017. See Appendix Table 4 for the full list of articles. 
In total, I found 45 articles. The earlier papers typically use data with coarse spatio-temporal resolution whereas it becomes more common to rely on daily or even intra-daily data with high spatial resolution over time. Clustering on spatial entities is also very common except in the earliest papers, but only a few papers go any further in their treatment of spatial dependence such as applying Conley (1999) standard errors. Moreover, only a handful of papers apply spatiotemporal time trends that would alleviate the problems of spurious relationships studied herein. Finally, I found only one paper (Madestam et al., 2013) that re-samples rainfall to check the validity of their findings.

Starting with Gomez et al. (2007) and Hansford \& Gomez (2010), there is also by now a fairly large literature on the relationship between election day weather and turnout. Beyond the US, the question has been studied in Japan, Holland, Spain, Italy, Sweden, Germany, Norway, and South Korea (Horiuchi \& Saito, 2009; Eisinga et al., 2012b,a; Artés, 2014; Sforza, 2013; Lo Prete \& Revelli, 2014; Persson et al., 2014; Arnold \& Freier, 2016; Lind, 2014; Kang, 2018). In many studies, it is found that rain on election day reduces turnout, but in Sweden there seems to be essentially no relationship between the two and in Norway the relationship is positive. It has also been argued that election day affects political outcomes either by affecting the composition of voters (Gomez et al., 2007; Lind, 2014) or by affecting the preferences of voters (Meier et al., 2016). Daily weather conditions have also been found to have an impact on participation in civil rights riots in the 1960s (Collins \& Margo, 2007), Tea Party rallies (Madestam et al., 2013), and May day demonstrations (Kurrild-Klitgaard, 2013).

\subsection{Other explanations}

[Figure 2 about here.]

As already illustrated, regressions with rainfall as the independent variable seems to yield a distribution of t-values that differ markedly from the theoretical standard normal distribution. They are not normally distributed, ${ }^{13}$ but the main problem is that the standard deviation is much higher than unity. In the basic specification shown in Figure 1, the standard deviation of the t-statistics is 4.37 - and a test of the hypothesis if it being unity rejects vastly. 
Before exploring the explanation based on spatio-temporal trends further, it is worthwhile dispensing with the alternative explanation of outliers in precipitation. It is well known that rainfall data has a heavy right tail, which could affect the regression analyses. To show that this cannot be the sole explanation, Figure 2 shows the distribution of the t-values in a number of specifications that reduces the leverage of outliers. Panel (a) is the specification shown in the introduction, where the level of turnout is regressed on the level of rain in millimeters. Panels (b) and (c) replace the measure of precipitation with dummies for substantial rain, defined as above $2.5 \mathrm{~mm}$, and any rain at all. Finally, in Panel (d) both rainfall and turnout are measured using their ranks so they both have a uniform distribution on the unit interval. In all four cases, the distribution of the test statistic is far from the standard normal or t-distributions we would expect. This should indicate that mere outliers cannot explain the findings.

Another possible explanation could be spatially varying annual patterns in precipitation. Although most Norwegian municipalities have higher average precipitation during winter than summer, there is some variation to the pattern which is spatially correlated. In a dataset with several observations each year, this phenomenon can generate spurious correlations between rainfall and other spatially correlated variables - and the problem would be easily solved by controlling for seasonality. Parliamentary elections in Norway, however, are always held mid-September. Hence on election days, municipalities are always at the same stage of their climatic seasonal cycle. In the simulations, where we consider election day $\pm t$ days, we also end up with observations in the same phase of the cycle. Consequently, seasonal patterns can not be the explanation for the phenomenon.

\subsection{Omitted spatially dependent variables}

[Figure 3 about here.]

Rather, it seems that the nature of the problem is omitted variables exhibiting spatio-temporal trends and potentially spatial non-stationarity ${ }^{14}$ in the rainfall data in combination with spatio- 
temporal trends in the turnout data. To explore the latter trends, I run a regression of the type

$$
\text { Turnout }_{i t}=\alpha_{i}+\tau_{t}+\delta_{i} t+\epsilon_{i t} \text {. }
$$

Here $\delta_{i}$ is an estimate of the municipality specific trend. I have plotted the values of $\delta_{i}$ in Figure 3 . Panel (a) shows the geographical distribution of temporal trends. It is clear that there is a strong negative trend in the eastern part of the country and a positive trend in parts of the west and the center. Panel (b) shows a Moran plot where the municipality specific coefficient $\delta_{i}$ is plotted against the average $\delta_{i}$ in the adjacent municipalities. Again, it is clear that there is a spatial pattern. Formally, Moran's I statistic is $I=0.456$ and the Moran test for no spatial dependency rejects with a p-value of $2.2 \times 10^{-16}$. We conclude that when controlling for two way fixed effects, turnout has been declining in the eastern part of the country and increasing in the western part. As shown in Sections 3.1 and 3.2, this can explain the t-values shown in Figure 2.

[Table 1 about here.]

Hence it seems that variables with spatial dependence may correlate spuriously with rainfall. To show this more forcefully, I run some simulations. There are many ways of running these simulations and obtaining spurious results. Here I have chosen a very simple specification which is clearly nonsensical, and still correlates strongly with rainfall.

The independent variable is the observed rainfall in Norwegian municipalities on a random day between January 1st 1968 and November 30th 2012. ${ }^{15}$ First, I consider a cross sectional setting where I simulate dependent variables

$$
z_{i}=x_{i}+y_{i}+\epsilon_{i}
$$

where $x_{i}$ and $y_{i}$ is the longitude and latitude of the municipal center of municipality $i$ and $\epsilon_{i}$ is a standard normally distributed residual. Regressing $z_{i}$ on observed rainfall yields the results shown in Row 1 of Table 1. The full distributions are shown in Appendix Figure 9. As this is cross sectional data, season patterns are not present in the data. As in the example above, we see 
massive over rejection of false null hypotheses: Here the test at the $5 \%$ level rejects in $84 \%$ of cases.

To account for the spatial pattern, I also attempt to cluster standard errors at the 19 regions of Norway as well as using Conley (1999) standard errors. Both approaches seems to have about the same effects of increasing the standard errors. However, as can be seen from Rows 2 and 3 of Table 1, we still have rejection of the false null in $59 \%$ of cases using a $5 \%$ test. Moreover, we notice that this tends to yield a heavily skewed distribution of the t-values. First, this indicates that at least a substantial part of the problems lies in the estimated regression coefficient $\hat{\beta}$, not in the computation of the standard errors. In some ways, this is unsurprising as biased regression coefficients are well known results from omitted variables problems. Second, it tells us that the problem can not be solved by correcting the standard errors alone.

I also ran simulations as above, but where municipalities were assigned rainfall data from a randomly selected municipality. This maintains the distribution of the independent variable but removes the spatial pattern. As we can see from Row 4 of Table 1, we now get almost a perfect replication of the standard normal distribution. This indicates that the cause of the problem is the spatial correlations and not the skewed distribution of the rainfall data.

A typical way to control for such spatial patterns is to include municipal fixed effects, as was done in the analysis of the turnout data above. As long as the dependent variable only exhibits spatial correlation, this solves the problem. If, however, the variable has a spatially dependent trend, fixed effects can't solve the problem. To illustrate this, I draw panels starting on a random day, with observations every four years and totally 10 observations per municipality. As all observations are on the same date, seasonal patterns are not present in the data. I then construct a dependent variable as

$$
z_{i t}=\left(x_{i}+y_{i}\right) t+\epsilon_{i t}
$$

where again $x_{i}$ and $y_{i}$ are the longitude and latitude of the municipality and $t$ the year. Regressing $z_{i t}$ on observed rainfall yields the results shown in Row 5 of Table 1. Again, the false null is over rejected, this time in $81 \%$ of cases for the $5 \%$ test. 


\section{A GENERAL EXPOSITION OF THE PROBLEM}

\subsection{A theoretical approach}

To get a better grasp of the nature of the problem at hand, I develop a simple econometric model that is able to generate the phenomenon and may approximate the problem in real world situations. The results of the model resemble those found by Granger et al. (2001) in the case of time series, but certain features are better adapted to a spatial setting. Specifically, we want to show that a spatially correlated explanatory variable that is in reality irrelevant may seem relevant - hence generating a pattern of spurious correlation.

Consider a case where space is reduced to one dimension, so observations can be represented as points $i=1, \ldots, N$ on a line. We generate an explanatory variable $r_{i}$ as the sum of a number of $K$ spatially correlated shocks. Specifically, each shock has a location ${ }^{16} p_{k} \in[1, N]$ and a value $\nu_{k}$ drawn from some continuous distribution. In the case of precipitation, we may think of each shock as a weather system with intensity $\nu_{k}$ and center at $p_{k}$. At position $i$, the total effect of shocks is $r_{i}=\sum_{k} \frac{\nu_{k}}{1+d\left(i, p_{k}\right)}$ where $d$ is a distance function which satisfies $d(i, i)=0$ and where $d(i, j)$ is increasing in $|i-j|$. Notice that this is essentially a radial basis function network, which is commonly used to approximate functions (Buhmann, 2003). Hence this model should approximate a wide range of spatial patterns found in real life.

The outcome variable of interest $y_{i}$ depends on a number of unobserved variables, some of which are spatially correlated. In the theoretical exposition, we model these are resulting in a spatial trend $\tau i$ for some trend parameter $\tau$, so the outcome variable is given by

$$
y_{i}=\alpha+\beta r_{i}+\tau i+\epsilon_{i} .
$$

We may suspects that $r_{i}$ also enters equation (3) with a slope $\beta$. Hence we want to test the hypothesis that $\beta=0$. Using conventional tools, we would disregard the spatial trend $\tau i$. The core of the problem, as we see below, is that a regression of $y_{i}$ on $r_{i}$ mixes up the trend $\tau i$ and the signal $r_{i}$. 
[Figure 4 about here.]

In the theoretical exposition, I focus on the metric $d(i, j)=|i-j|$ and the case with only one shock $p$, i.e. $K=1$. This case is illustrated in Figure 4. As is apparent from the figure, whenever the "position" of the shock is $p \neq \frac{N}{2}$, there is scope for the shock to pick up parts of the trend. We want to show this formally and see how a test is affected by an increasing sample size $N$. It turns out that in this case, the problem does not diminish but rather get more acute.

When the data are generated as in equation (3), but where we fail to control for the trend $\tau_{i}$ in the analysis, the OLS estimator becomes

$$
\hat{\beta}=\beta+\frac{\frac{1}{N} \sum\left(r_{i}-\bar{r}\right) \epsilon_{i}}{\frac{1}{N} \sum\left(r_{i}-\bar{r}\right)^{2}}+\tau \frac{\frac{1}{N} \sum\left(r_{i}-\bar{r}\right) i}{\frac{1}{N} \sum\left(r_{i}-\bar{r}\right)^{2}} .
$$

When $\epsilon_{i} \sim \operatorname{iid}\left(0, \sigma^{2}\right)$ the first fraction converges in distribution to a well-behaved normally distributed term by application of the central limit theorem. This is handled by ordinary estimation and hypothesis testing procedures. The second term, which stems from the omitted variable, however, is the root of the problem. In finite samples it is non-zero unless $p=\frac{N}{2}$. Moreover, the problem is exacerbated with growing sample sizes, as the following result demonstrates:

Proposition 1. When $N \rightarrow+\infty$ and $\frac{K}{N} \rightarrow \kappa<+\infty$, we have $\operatorname{Pr}(|\hat{\beta}-\beta| \rightarrow+\infty)=1$.

The full proof is provided in Appendices B.1 and B.2. Denote by $\bar{w}$ the average $\bar{w}=\frac{1}{N} \sum_{i=1}^{N} \sum_{k=1}^{K} \frac{1}{1+\left|p_{k}-i\right|}$. In Appendix B.1 I show that the expression $\frac{1}{N} \sum_{i=1}^{N} \sum_{k=1}^{K}\left(\frac{1}{1+\left|p_{k}-i\right|}-\bar{w}\right) i$ converges to a logarithmic function and hence diverges as $N \rightarrow \infty$. The proof is based on showing that the expression can be sandwiched between two harmonic sequences which both have logarithmic growth. Moreover, in Appendix B.2 I show that if $\frac{K}{N} \rightarrow \kappa \in \mathbb{R}^{+}$, we have that as $N \rightarrow \infty$, the denominator $\frac{1}{N} \sum_{i=1}^{N} \sum_{k=1}^{K}\left(\frac{1}{1+\left|p_{k}-i\right|}-\bar{w}\right)^{2} \rightarrow Q \in \mathbb{R}^{+}$. This is based on showing that $\sum_{i=1}^{N} \sum_{k=1}^{K}\left(\frac{1}{1+\left|p_{k}-i\right|}-\bar{w}\right)^{2}$ is closely related to the sum of reciprocals of squares of natural numbers. The sum of this sequence is known to converge to $\frac{\pi^{2}}{6}$. As a consequence, the sum at hand also converges to a constant. Consequently, the expression goes to 0 at rate $O\left(\frac{1}{N}\right)$. If on the other hand we allow $K$ to grow linearly as $N$ grows, the denominator converges to a constant. 
In both cases, the estimator $\hat{\beta}$ explodes and hence is inconsistent. However, unlike conventional omitted variables biases, the sign of the bias is random.

In applied research much emphasis is on statistical significance, i.e. the t-values. As the denominator in (4) converges to a constant, the standard error of $\hat{\beta}$ also converge to a constant. As $\hat{\beta}-\beta$ diverges, this implies that the t-values also diverge. This could hence explain the unusually high t-values observed above.

One objection to this analysis could be that as $N$ increases, the size of space, and hence the range of $r_{i}$, increases. An alternative model could be to restrict space to say $[0,1]$ and increase the density of observations as $N$ increases. Then the trend should be modeled as $\frac{\tau i}{N}$, and the distance metric for the shocks replaced by $\left|\frac{i}{N}-\frac{p_{k}}{N}\right|$. However, it is easily seen that in computing OLS estimates, this does not change the final expression and hence the regression estimate still diverges as $N$ increases.

The above results depends on the the specification of $r_{i}$ being proportional to the inverse of the distance. If the weighting decays more quickly, a may be realistic in many applications, the proof of divergence has to be changed. ${ }^{17}$ However, it seems that the main insight would go through with other specifications of the weighting too.

\subsection{Monte Carlo evidence}

The results presented in Section 3.1 apply to a stylized model. To illustrate that these results are more general, I now report results from a number of Monte Carlo analyses on varieties of this model.

Table 2 shows a Monte Carlo analysis of the model from Section 3.1 for sample sizes between 10 and 10000 and number of shocks varying from 1 to 20000. The simulations are based on a model where the true $\beta=0$ so the fraction of t-tests rejecting the null should correspond to the level of the test, here $5 \%$. First, we recognize the diverging t-values: The larger the sample gets, the more likely the t-test is to reject. The test at the $5 \%$ level rejects in about half of the cases for small samples and in more than $80 \%$ of cases in larger samples. ${ }^{18}$ Rejections rates and values of $|t|$ are slightly smaller for larger numbers of shocks, but this is not enought to take levels down 
to reasonable magnitudes.

[Table 2 about here.]

In many real world applications, the assumption of a linear world is too restrictive. ${ }^{19} \mathrm{~A}$ more realistic assumption is a spatial data structure where it is meaningful to talk about the distance between two observations, and where units tend to be correlated with nearby units. Denoting observation $i$ 's geographical position $\left(x_{i}, y_{i}\right)$, we can use the Euclidean distance function $d(i, p)=$ $\sqrt{\left(x_{i}-x_{p}\right)^{2}+\left(y_{i}-y_{p}\right)^{2}}$. A linear geographical trend can be defined as $\tau_{i}=\tau_{x} x_{i}+\tau_{y} y_{i}$ for constants $\tau_{x}$ and $\tau_{y}$. Such trends, sometimes with more sophisticated specifications, are widespread in geographical data and their study goes at least back to Krumbein $(1959 ; 1963)$ and Tobler (1969).

Without going into the formalism, it is easily seen that this model is essentially equivalent to the model studied in Section 3.1, and hence that the same problems arise. Monte Carlo analyses reported in Appendix Table 5 also show that the problem is indeed still present and if anything stronger than in the basic model.

In many applications including most of those mentioned in the introduction, we have access to a panel of observations. This allows for controlling for unit fixed effects, which would rule out the problem of the spatial trend $\tau_{i}$. Time trends are also unproblematic as they are routinely handled by year dummies. But if time trends depend on geography, that is we have spatio-temporal trends, the problem studied above reappears. Consider the case where

$$
z_{i t}=\alpha_{i}+\beta r_{i t}+\tau_{i} t+\epsilon_{i t}
$$

with the trend $\tau_{i}=\tau_{x} x_{i}+\tau_{y} y_{i}$ for constants $\tau_{x}$ and $\tau_{y}$. If we assume a balanced panel so we can differentiate expression (5), we get

$$
\Delta z_{i t}=\beta \Delta r_{i t}+\tau_{i}+\Delta \epsilon_{i t}
$$

which essentially is specification (3). De-meaning of course yields similar results. The only major difference is that we look at differenced shocks (or deviations from means). However, these have 
the exact same properties of spatial correlation as the undifferenced shock, so the issues studied in Section 3.1 still remain. Monte Carlo simulations of this model also yield very similar conclusions - the null hypothesis of no relationship which should have been rejected in $5 \%$ of cases is rejected far too often and t-values are typically high. ${ }^{20}$ Moreover, the problem is exacerbated by increasing sample sizes. There are some indications that increased panel lengths reduces the problem. As time periods are independent of each other, increasing $T$ increases the (random) variation in $\Delta r_{i}$ which helps uncover its independence to $\Delta z_{i t}$.

The mechanism generating the spurious rejections of hypothesis tests above is that the precipitation shocks in sum are non-zero and with opposite sign in different corners of space. With a spatial trend, the two combine to form spurious correlation. The assumption of a deterministic spatial (or spatio-temporal) trend may be too strong in certain applications. However, the problem may persist in more general models of spatial dependence.

Consider a model in one-dimensional space of the form

$$
\begin{aligned}
& y_{i}=\alpha+\beta r_{i}+u_{i} \\
& u_{i}=\rho u_{i-1}+\epsilon_{i},
\end{aligned}
$$

i.e. a simple first order auto-regressive model. ${ }^{21}$ Unbiased test of the hypothesis $\beta=0$ depends on $E \sum_{i} r_{i} u_{i}=0$. With the current specification, we have $u_{i}=\sum_{j=0}^{i-1} \rho^{j} \epsilon_{i}$. Say for simplicity that the location $p$ is at an integer. Then

$$
\sum_{i} r_{i} u_{i}=\sum_{j=0}^{N-p} \frac{\nu}{1+j} u_{j+p}+\sum_{j=1}^{p-1} \frac{\nu}{1+j} u_{p-j} .
$$

Using the autoregressive structure of the residuals, this can be rewritten

$$
\sum_{i} r_{i} u_{i}=\sum_{i=1}^{N} \epsilon_{i} \sum_{j=0}^{N-1} \frac{\nu}{1+|p-i+j|} \rho^{j}
$$

With high spatial dependence (i.e. $\rho$ close to unity), the loading on a few of the innovations $\epsilon_{i}$ close to $p$ is going to be large, and these innovations determine the whole estimated $\beta$. Even as $N$ 
gets large, this effect persists.

For $K>1$, we compare the loading on $\epsilon_{i}$ around several clusters. Still, some of the clusters dominate and hence the bias remains the same if not worse. ${ }^{22}$ Moreover, when the spatial dependency is high ( $\rho$ is close to unity), we get spurious relationships in the vast majority of cases. Increasing the sample size or the number of shocks does not seem to improve the situation.

\section{DETECTING AND SOLVING THE PROBLEM}

In the case of the weather, the problem of spurious correlations can usually be detected by examining the weather at counterfactual dates as in Figure 1. With other independent variables, other placebos may be feasible. If rejection rates differ markedly from the expected rates, some spatial or spatio-temporal dependency may be the explanation although of course other explanations obviously also exist. The next step should be to try to get some impression of the spatial dependency. One way to do this is to simply plot maps of spatial values or estimated spatial trends. In some cases it may also be useful to use testing procedures such as Moran's I statistic.

If a spatial pattern is found, two possible solutions can be pursued. The ideal solution is to find the source of the dependency and expand the model specification to take this into account. If, for instance, geographically varying trends are due to geographical differences in demographic patterns (say young people moving toward large cities), one could potentially solve the problem by adding demographic controls. However, it may not always be easy to find a simple explanation and there may not be a single explanation for the geographical trend. In such cases, it may be a better option to attempt to control for the geo-spatial trend. In the time series literature, this is usually done by simply including the date as a variable, sometimes with a few polynomial terms. In the case of geographical data, this may be too limiting.

In the cross sectional case, we want to control for some unknown function $T(x, y)$. As the shape of $T$ is unknown, a flexible estimator in two-dimensional space is called for. Kernel based and other standard non-parametric estimators are computationally intensive, and as their rate of convergence is typically below $\sqrt{n}$, inference of the other variables in the regression can't always be made using standard techniques. Consequently, a simpler form may be advisable. 
In the case of a panel, we need to estimate a function $T(x, y, t)$. As this is a function of three variables, a fully flexible non-parametric approach gets even more demanding. At least for short panels, it seems reasonable that the trend may be kept linear, so we can rewrite $T(x, y, t)=U(x, y) t$ for some function $U$. One solution that seems to work well for the electoral turnout data considered below is one where $U$ is specified as a tensor product of Legendre polynomials. ${ }^{23}$ The choice of orthogonal polynomials is to reduce problems of multicollinearity and improve numerical stability. One justification for choosing Legendre polynomials is their orthogonality property with regard to an $L^{2}$ inner product given a uniform spatial distribution of units. Although the distribution is not exactly uniform, this approach is likely to give better behavior than most other orthogonal polynomial bases that provide orthogonality given various bell shaped distributions. Still, it seems that the choice of polynomial base has little effect on the final outcomes.

Given dimensionalities $K$ and $L$, we can specify

$$
T(x, y, t)=t \sum_{k=0}^{K} \sum_{\ell=0}^{L} \theta_{k \ell} P_{k}(x) P_{\ell}(y)
$$

where $P_{i}(\cdot)$ is the $i$ 'th order Legendre polynomial. ${ }^{24}$ The $(K+1)(L+1)$ parameters $\theta_{k \ell}$ can be estimated together with the other parameters in an ordinary regression model.

The choice of the dimensions $K$ and $L$ has to be chosen to make the polynomial (7) provide a reasonable fit of the data. If $K$ and $L$ are chosen too high, there is both a danger of over fitting (Hastie et al., 2008, Ch. 7) and loosing so much variation that it becomes impossible to identify the effect of the variable of interest. Hence we want would like a good fit with a low dimensional polynomial. To make a good trade off, I recommend to consider choosing $K$ and $L$ by maximizing a linear penalty function

$$
R^{2}-\xi(K+1)(L+1)
$$

where $R^{2}$ is the fit of the model and $\xi$ a penalty on the number of parameters to estimate. This is closely related to maximizing the AIC and BIC criteria, but varying the degrees of freedom penalty. Varying the parameter $\xi$, we can trace out the class of potentially good polynomial compositions. 
It is also important to undertake counter factual estimations as in Figure 1 to check that the polynomial at hand actually solves the problem. If the fit is good enough, most of the placebo variables should have little effect on the outcome. Another approach could also be to choose $K$ and $L$ high, but constrain the $\theta_{k \ell}$ by employing ridge regression, LASSO, or other versions of constrained estimation (Belloni et al., 2014; Hastie et al., 2008, Ch. 3).

\section{TURNOUT IN NORWEGIAN ELECTIONS}

Let us now return to the application considered in the introduction, the effect of rainfall on electoral turnout in Norwegian municipal elections. The data are described in Appendix C.

\subsection{Specifying the spatio-temporal trend}

As argued in Section 4, one way to handle the problem of spation-temporal trends is to control them out in the estimation. I approximate the trend with the tensor product of Legendre polynomials. The first step needed is to make a choice of how many polynomial terms to include in each of the two dimensions. Figure 5 shows the the model's fit (net of a baseline model without spatio-temporal controls) for each combination of between 0 and 10 terms in each dimensions. Combinations of polynomial orders $K$ and $L$ that are maxima of the penalized model (8) for some value of $\xi$, i.e. those which are elements of the convex hull of the points, are shown in red. There is a strong increase in fit going up to about 15 terms, then the effect of additional terms seems to flatten out. To avoid over fitting the data and preserve some degrees of freedom, my preferred model specifies spatio-temporal trends using a first order polynomial in the longitude and a sixth order polynomial in the latitude, using 13 terms and increasing the fit as measured by $R^{2}$ by 0.083 .

[Figure 5 about here.]

Adding more terms not only have a minor impact on the model's fit, it turns out that the exact specification of the spatio-temporal has little importance once we reach a minimum level of complexity. Figure 6 shows the distribution of t-values for eight specification with increasing complexity of the tensor product of Legendre polynomials and regional dummies and with linear 
and quadratic time trends. ${ }^{25}$ The distributions are almost perfectly overlapping for each of the eight models. Indeed, the correlation between the most and the least complex models are between .85 and .9 .

Moreover, we notice that the distribution of t-values is much more well behaved than the t-values obtained without controlling for spatio-temporal trends. Although the distribution is somewhat fatter than the theoretical Student's t distribution, the distribution is much more sensible to work with.

Finally, it seems that using region specific trends has a comparable effect in improving estimation results to spatio-temporal trends. As argued above there are many cases where it is implausible that the trend has a spatial discontinuity at regional borders. Still, it seems that this potential mis-specification has little impact in practice.

[Figure 6 about here.]

\subsection{The effect of rainfall on turnout}

Table 3 shows the actual estimation results regressing turnout on election day weather. First, specifications (1) and (2) show the estimation results using a two-way fixed effects specification without controlling for spatio-temporal trends. The simplest specification indicate that rainfall does not affect turnout. When we interact rainfall with a time trend, it seems that rainfall suddenly has a time-varying effect. In Panel A of Appendix Table 8 I show some additional specifications, where signs and significance levels are even more erratic. As argued above, this specification is probably not trustworthy.

In specifications (3) and (4) of Table 3, I show the estimation results from the preferred specifications. The general pattern is that rain seems to increase turnout in Norway - see Lind (2014) for a discussion of the rationale behind this. Column (1) shows the plain regression of turnout on precipitation in $\mathrm{cm}$. The effect of $1 \mathrm{~cm}$ increase in precipitation is about .3 percentage point increase in turnout. Columns (2) includes a time interaction. We see that with this specification, the results seem to be stable over time as the interaction is insignificant. In Panel B of Appendix Table 8 I include the same specifications as above. Now, the picture arising is homogenous across 
specifications indicating a much more stable specification.

[Table 3 about here.]

\section{CONCLUSION}

In this paper, I have shown that when outcomes of interest are regressed on weather data, there is a danger of spuriously detecting relationships. To illustrate the occurrence of the problem, I have shown nonsensical relationships such as a relationship between electoral turnout and rainfall 100 days before the election. In such cases, the relationship can be rejected by common sense. But for more relevant questions, such as whether rain on the day of the election affect turnout, the problems of spatial correlation remain the same. To give a satisfactory answer in the potentially interesting cases, we need a proper understanding of the phenomena generating the spurious relationships.

The reason for these relationships, I argue, is that spatial patterns in weather conditions are likely to align up with spatial or spatio-temporal patterns in the outcomes of interest. I have shown that this does indeed occur in a simple model of spatially dependent data as well as in an extensive range of Monte Carlo analyses. Moreover, the analyses reveal that standard techniques, such as clustering on spatial entities (Moulton, 1986) or using Conley's (1999) approach to computing standard errors does solve the problem.

Rather, I suggest introducing controls for spatial or spatio-temporal trends in regressions to solve the problem. This is a simple remedy that can easily be combined with other techniques, such as instrumental variables of regression discontinuity designs. In a sample of Norwegian municipal elections, I show that this reduces the problem of spurious relationships in statistical tests to close to the theoretical properties.

The question of more sophisticated approaches to controlling for spatial and spatio-temporal trends, possibly borrowing from the literature on spatial statistics and econometrics is left for future research. There are probably possibilities to do better, but it is unclear that such approaches are sufficiently simple to implement that they actually matter for the applied researcher.

In studies of the effect of short term weather changes, as studied in this paper, weather data are typically available for a large number of periods, of which only a few matter. Then there is 
ample supply of placebo data. Such data should regularly be used to test the validity of empirical approaches used. In studies of the effect of long term weather effects, such as the effect on agricultural production, surplus data are harder to find. Still it may be possible to run placebo studies by temporally moving the whole or parts of the rainfall pattern.

When placebo data can be constructed, one may also ask whether these they could be used to construct a more correct null distribution of the parameter of interest, somewhat along the lines of bootstrapping techniques. Saunders (1993) implements a version of this estimator, but does not go into its statistical properties and potential advantages compared to ordinary inference.

\section{ACKNOWLEDGEMENT}

I am grateful for useful comments from Monique de Haan, Andreas Kotsadam, Kyle Meng, Per Pettersson-Lidbom, and participants at the $(\mathrm{EC})^{2}$ conference, the Oslo Empirical Political Economics workshop, and seminar participants at the University of Oslo. I also got invaluable help with the meteorological data from Ole Einar Tveito. While carrying out this research I have been associated with the center Equality, Social Organization, and Performance (ESOP) at the Department of Economics at the University of Oslo. ESOP is supported by the Research Council of Norway through its Centres of Excellence funding scheme, project number 179552. 


\section{Notes}

${ }^{1}$ As pointed out by Miller (2015), however, although weather phenomena are exogenous, they may in many cases be predicted in advance.

${ }^{2}$ An econometric model that properly models the spatially correlated patten of rainfall as well as other variables of interest might be able to yield correct results. However, no such model is readily available to practitioners and in the fairly extensive literature reviewed below, no such attempts are made.

${ }^{3}$ The estimation uses data from ten elections between 1971 and 2007 using a two way fixed effects specification Turnout $_{i t}=\alpha_{i}+\tau_{t}+\beta_{s}$ Rainfall $_{i, t+s}+\epsilon_{i t}$ for $s \in[-600,600]$. To account for possible correlations between rainfall on election day $t$ and day $t+s$, I also consider the specification Turnout ${ }_{i t}=\alpha_{i}+\tau_{t}+\beta_{s}^{0} \operatorname{Rainfall}_{i, t}+\beta_{s} \operatorname{Rainfall}_{i, t+s}+\epsilon_{i t}$. See Section 5 for further details and Appendix C for a description of the data.

${ }^{4}$ Results remain the same if one looks at dummies for precipitation above different thresholds, normalize by municipality means or variances, normalize the turnout variable and so on, which all should be robust to heavy tailed distributions.

${ }^{5}$ Parliamentary elections are always held in mid-September in Norway. This means that in the simulations behind Figure 1, we compare precipitation at almost the same date in all 1200 replications.

${ }^{6}$ As an example, I also regressed median gross income by municipality and year on rainfall on every day of the year, one day a time. The distribution of the t-values are shown in Appendix Figure 8. A $5 \%$ test of the (probably) true null hypothesis of no relationship rejects on $62.5 \%$ of days. One could expect to find a relationship between income and rainfall in countries with a large agricultural sector (Paxson, 1992), but in that case only between rainfall over longer periods of time. Moreover, Norway does not have an important agricultural sector any more.

7 The problem is not unique to rainfall. First, various terrain characteristics such as ruggedness and gradients, the use of which was popularized by e.g. Duflo \& Pande (2007), clearly exhibit spatial correlation. In the empirical analysis of violent conflict, for instance, researchers have found strong spatial and spatio-temoral patterns (see e.g. Buhaug \& Gleditsch, 2008; Weidmann \& Ward, 2010). There is also a vast literature on the spatial and spatiotemporal nature of housing and property prices (see e.g. Holly et al., 2011; Brady, 2014). More examples could easily be listed. In all these cases, there is a danger of spurious relationships stemming from joint spatial patterns.

${ }^{8} \mathrm{~A}$ number of papers using rainfall as an exogenous source of variation, e.g. Brückner \& Ciccone (2011) and Fujiwara et al. (2016), also include spatially varying trends. However, it is not yet well understood why this is necessary and hence the practice is not as widespread as it probably should be.

${ }^{9}$ Cressie (1993) and Ripley (2004) provide introductions to parts of the literature.

${ }^{10}$ See e.g. LeSage \& Pace (2009) for an introduction.

${ }^{11}$ See also Matsui et al. $(2011,2014)$ for some recent development.

${ }^{12}$ See Dell et al. (2014) for a survey of parts of this literature. 
${ }^{13}$ We can reject normality for all the t-values for all the four specification shown in Figure 2 using most conventional tests and significance levels. The reason is mostly the low kurtosis.

${ }^{14}$ Spatial non-stationarity is commonly found in meteorological data even after demeaning, see e.g. Fuglstad et al. (2015) and Ingebrigtsen et al. (2015). However, to the best of my knowledge no general procedure for formally testing for stationarity exists.

${ }^{15}$ See Appendix $\mathrm{C}$ for details on the meteorological data.

${ }^{16}$ For simplicity I condition on given values of $p_{k}$, but little would change if these were drawn from some continuous distribution on $[0, N]$.

${ }^{17}$ Typically one can show that although the numerator in (4) converges to zero, the denominator converges at a higher rate so the fraction diverges.

${ }^{18}$ These numbers could of course be reduced by increasing the noise, i.e. increasing the variance of $\epsilon_{i}$, but this does not reduce the importance of the problem.

${ }^{19}$ An exception is time series data, but the current modeling of shocks does not seem particularly relevant to that case.

${ }^{20}$ See Appendix Table 6 for details.

${ }^{21}$ To simplify, correlation is only to the left. The model would be essentially unchanged if $u_{i}$ was correlated with both $u_{i-1}$ and $u_{i+1}$.

${ }^{22}$ Results are reported in Appendix Table 7

${ }^{23}$ See e.g. Judd (1998, Ch. 6) for an overview of Legendre polynomials and other polynomial basis with applications in economics and Totik (2005) for the mathematical background.

${ }^{24}$ These polynomials are usually defined recursively with $P_{0}(x)=1, P_{1}(x)=x$, and for $i \geq 2, P_{i}(x)=$ $\left[(2 i-1) x P_{i-1}(x)-(i-1) P_{i-1}(x)\right] / i$ where the variable $x$ is normalized to be in the interval $[-1,1]$.

${ }^{25}$ The distribution of the estimated coefficients can be found in Appendix Figure 10 


\section{References}

Arnold, F., \& Freier, R. (2016). Only conservatives are voting in the rain: Evidence from German local and state elections. Electoral Studies, 41, 216 - 221.

Artés, J. (2014). The rain in spain: Turnout and partisan voting in Spanish elections. European Journal of Political Economy, 34, 126 - 141.

Barrios, T., Diamond, R., Imbens, G. W., \& Kolesár, M. (2012). Clustering, spatial correlations, and randomization inference. Journal of the American Statistical Association, 107(498), 578591.

Belloni, A., Chernozhukov, V., \& Hansen, C. (2014). Inference on treatment effects after selection among high-dimensional controls. The Review of Economic Studies, 81(2), 608-650.

Bertrand, M., Duflo, E., \& Mullainathan, S. (2004). How much should we trust differences-indifferences estimates? The Quarterly Journal of Economics, 119(1), 249-275.

Brady, R. R. (2014). The spatial diffusion of regional housing prices across U.S. states. Regional Science and Urban Economics, 46, 150 - 166.

Brückner, M., \& Ciccone, A. (2011). Rain and the democratic window of opportunity. Econometrica, $79(3), 923-947$.

Buhaug, H., \& Gleditsch, K. S. (2008). Contagion or confusion? Why conflicts cluster in space. International Studies Quarterly, 52(2), 215-233.

Buhmann, M. D. (2003). Radial basis functions: theory and implementations. Cambridge University Press.

Chudik, A., Pesaran, M. H., \& Tosetti, E. (2011). Weak and strong cross-section dependence and estimation of large panels. The Econometrics Journal, 14(1), C45-C90.

Cliff, A. D., Haggett, P., Ord, J. K., Bassett, K. A., \& Davies, R. B. (1975). Elements of spatial structure: A quantitative approach. Cambridge University Press. 
Collins, W. J., \& Margo, R. A. (2007, 12). The economic aftermath of the 1960s riots in American cities: Evidence from property values. The Journal of Economic History, 67, 849-883.

Conley, T. (1999). GMM estimation with cross sectional dependence. Journal of Econometrics, 92(1), $1-45$.

Cressie, N. A. C. (1993). Statistics for spatial data. John Wiley \& Sons.

Dell, M., Jones, B. F., \& Olken, B. A. (2014). What do we learn from the weather? The new climate-economy literature. Journal of Economic Literature, 52(3), 740-98.

Duflo, E., \& Pande, R. (2007). Dams. The Quarterly Journal of Economics, 122(2), 601-646.

Eisinga, R., Grotenhuis, M., \& Pelzer, B. (2012a). Weather conditions and political party vote share in Dutch national parliament elections, 1971-2010. International Journal of Biometeorology, $56(6), 1161-1165$.

Eisinga, R., Grotenhuis, M., \& Pelzer, B. (2012b). Weather conditions and voter turnout in Dutch national parliament elections, 1971-2010. International Journal of Biometeorology, 56(4), $783-$ 786.

Elhorst, J. P. (2001). Dynamic models in space and time. Geographical Analysis, 33(2), 119-140.

Fiva, J. H., Halse, A., \& Natvik, G. J. (2012). Local government dataset. (Dataset available from http://www.jon.fiva.no/data/FivaHalseNatvik2015.zip)

Fuglstad, G.-A., Simpson, D., Lindgren, F., \& Rue, H. (2015). Does non-stationary spatial data always require non-stationary random fields? Spatial Statistics, 14, Part C, 505-531.

Fujiwara, T., Meng, K. C., \& Vogl, T. (2016). Habit formation in voting: Evidence from rainy elections. American Economic Journal: Applied Economic, 8(4), 160-88.

Gelfand, A. E., Kim, H.-J., Sirmans, C. F., \& Banerjee, S. (2003). Spatial modeling with spatially varying coefficient processes. Journal of the American Statistical Association, 98(462), 387-396. 
Gomez, B. T., Hansford, T. G., \& Krause, G. A. (2007). The republicans should pray for rain: Weather, turnout, and voting in U.S. presidential elections. The Journal of Politics, 69(03), 649-663.

Granger, C., Hyung, N., \& Jeon, Y. (2001). Spurious regressions with stationary series. Applied Economics, 33(7), 899-904.

Granger, C., \& Newbold, P. (1974). Spurious regressions in econometrics. Journal of Econometrics, 2(2), $111-120$.

Hansford, T. G., \& Gomez, B. T. (2010). Estimating the electoral effects of voter turnout. American Political Science Review, 104(02), 268-288.

Hastie, T., \& Tibshirani, R. (1993). Varying-coefficient models. Journal of the Royal Statistical Society. Series B (Methodological), 55(4), 757-796.

Hastie, T., Tibshirani, R., \& Friedman, J. (2008). The elements of statistical learning: data mining, inference and prediction (2nd ed.). Springer.

Holly, S., Pesaran, M. H., \& Yamagata, T. (2011). The spatial and temporal diffusion of house prices in the UK. Journal of Urban Economics, 69(1), 2 - 23.

Hoover, D. R., Rice, J. A., Wu, C. O., \& Yang, L.-P. (1998). Nonparametric smoothing estimates of time-varying coefficient models with longitudinal data. Biometrika, 85(4), 809-822.

Horiuchi, Y., \& Saito, J. (2009). Rain, election, and money: The impact of voter turnout on distributive policy outcomes. (Mimeo, Yale)

Huang, J. Z., Wu, C. O., \& Zhou, L. (2002). Varying-coefficient models and basis function approximations for the analysis of repeated measurements. Biometrika, 89, 111-128.

Ingebrigtsen, R., Lindgren, F., Steinsland, I., \& Martino, S. (2015). Estimation of a non-stationary model for annual precipitation in southern Norway using replicates of the spatial field. Spatial Statistics, 14, Part C, 338-364. 
Judd, K. L. (1998). Numerical methods in economics. MIT Press.

Kang, W. C. (2018). The liberals should pray for rain: Weather, opportunity costs of voting and electoral outcomes in South Korea. (Mimeo, ANU)

Kelejian, H. H., \& Prucha, I. R. (1999). A generalized moments estimator for the autoregressive parameter in a spatial model. International Economic Review, 40(2), 509-533.

Kim, T.-H., Lee, Y.-S., \& Newbold, P. (2004). Spurious regressions with stationary processes around linear trends. Economics Letters, 83(2), 257-262.

Koopmans, T. C. (1949). Identification problems in economic model construction. Econometrica, $17(2), 125-144$

Krumbein, W. C. (1959). Trend surface analysis of contour-type maps with irregular control-point spacing. Journal of Geophysical Research, 64(7), 823-834.

Krumbein, W. C. (1963). Confidence intervals on low-order polynomial trend surfaces. Journal of Geophysical Research, 68(20), 5869-5878.

Kurrild-Klitgaard, P. (2013). It's the weather, stupid! individual participation in collective may day demonstrations. Public Choice, 155(3-4), 251-271.

LeSage, J., \& Pace, R. K. (2009). Introduction to spatial econometrics. CRC Press.

Lind, J. T. (2014). Rainy day politics - an instrumental variables approach to the effect of parties on political outcomes. (CESifo Working Paper No. 4911)

Lo Prete, A., \& Revelli, F. (2014, November). Voter turnout and city performance. (SIEP Working Paper 10)

Madestam, A., Shoag, D., Veuger, S., \& Yanagizawa-Drott, D. (2013). Do political protests matter? Evidence from the tea party movement. Quarterly Journal of Economics, 128(4), 1633-85. 
Matsui, H., Misumi, T., \& Kawano, S. (2011). Varying-coefficient modeling via regularized basis functions. ArXiv e-prints.

Matsui, H., Misumi, T., \& Kawano, S. (2014). Model selection criteria for the varying-coefficient modelling via regularized basis expansions. Journal of Statistical Computation and Simulation, $84(10), 2156-2165$.

Meier, A. N., Schmid, L. D., \& Stutzer, A. (2016). Rain, emotions and voting for the status quo. (IZA Discussion Paper 10350)

Miller, B. M. (2015). Does validity fall from the sky? Observant farmers and the endogeneity of rainfall. (Mimeo, UC San Diego)

Mohr, M. (2008). New routines for gridding of temperature and precipitation observations for seNorge.no. (met.no note 08/2008)

Moulton, B. R. (1986). Random group effects and the precision of regression estimates. Journal of Econometrics, 32(3), 385-397.

Paxson, C. H. (1992). Using weather variability to estimate the response of savings to transitory income in Thailand. American Economic Review, 82, 15-33.

Persson, M., Sundell, A., \& Öhrvall, R. (2014). Does election day weather affect voter turnout? Evidence from Swedish elections. Electoral Studies, 33, 335-342.

Pesaran, M. H., \& Tosetti, E. (2011). Large panels with common factors and spatial correlation. Journal of Econometrics, $161(2), 182-202$.

Pfeifer, P. E., \& Deutsch, S. J. (1980). A three-stage iterative procedure for space-time modeling. Technometrics, 22(1), 35-47.

Phillips, P. C. B. (1986). Understanding spurious regressions in econometrics. Journal of Econometrics, $33(3), 311-340$.

Ripley, B. D. (2004). Spatial statistics (2nd ed.). John Wiley \& Sons. 
Sarsons, H. (2015). Rainfall and conflict: A cautionary tale. Journal of Development Economics, $115,62-72$.

Saunders, E. M., Jr. (1993). Stock prices and Wall Street weather. The American Economic Review, 83(5), 1337-1345.

Sforza, A. (2013). The weather effect: Estimating the effect of voter turnout on electoral outcomes in Italy. (Mimeo, London School of Economics and Political Sciences)

Sims, C. A., Stock, J. H., \& Watson, M. W. (1990). Inference in linear time series models with some unit roots. Econometrica, 58, 113-144.

Tobler, W. R. (1969). Geographical filters and their inverses. Geographical Analysis, $1(3), 234-$ 253.

Totik, V. (2005). Orthogonal polynomials. Surveys in Approximation Theory, 1, 70-125.

Tveito, O. E., \& Førland, E. J. (1999). Mapping temperatures in Norway applying terrain information, geostatistics and GIS. Norwegian Journal of Geography, 53(4), 202-212.

Ventosa-Santaulària, D. (2009). Spurious regression. Journal of Probability and Statistics, Article ID 802975 .

Weidmann, N. B., \& Ward, M. D. (2010). Predicting conflict in space and time. Journal of Conflict Resolution, 54(6), 883-901.

Zhu, H., Fan, J., \& Kong, L. (2014). Spatially varying coefficient model for neuroimaging data with jump discontinuities. Journal of the American Statistical Association, 109 (507), 1084-1098. 


\section{A. EMPIRICAL LITERATURE USING RAINFALL}

[Table 4 about here.] 


\section{B. PROOFS}

B.1. Proof of divergence of the numerator in (4)

Proof. Let $\lceil\cdot\rceil$ and $\lfloor\cdot\rfloor$ denote the ceil and floor operators, that is, for any $x \in \mathbb{R}_{+},\lceil x\rceil=$ $\min \{y \in \mathbb{N}: x \leq y\}$ and $\lfloor x\rfloor=\max \{y \in \mathbb{N}: x \geq y\}$. Define the relative position of the location of a shock as $\zeta=\frac{p_{k}}{N}$. Finally define $\lambda=\lceil\zeta N\rceil-\zeta N$ (so $1-\lambda=\zeta N-\lfloor\zeta N\rfloor$ ). To study the behavior of $\frac{1}{N} \sum_{i=1}^{N} \sum_{k=1}^{K}\left(\frac{1}{1+\left|p_{k}-i\right|}-\bar{w}\right) i, \quad$ we need the behavior of $\sum_{i=1}^{N} \sum_{k=1}^{K} \frac{1}{1+\left|p_{k}-i\right|}$ and $\sum_{i=1}^{N} \sum_{k=1}^{K} \frac{i}{1+\left|p_{k}-i\right|}$.

1) The behavior of $\sum_{i=1}^{N} \sum_{k=1}^{K} \frac{1}{1+\left|p_{k}-i\right|}$ :

For simplicity of notation, we disregard the subscript $k$. We split the absolute value in the denominator into the terms with $i$ below and above $p=\zeta N$. This yields

$$
\begin{aligned}
\sum \frac{1}{|\zeta N-i|+1} & =\frac{1}{\lceil\zeta N\rceil-\zeta N+1}+\frac{1}{\lceil\zeta N\rceil-\zeta N+2}+\ldots+\frac{1}{\lceil\zeta N\rceil-\zeta N+(N-\lceil\zeta N\rceil)} \\
& +\frac{1}{\zeta N-\lfloor\zeta N\rfloor+1}+\frac{1}{\zeta N-\lfloor\zeta N\rfloor+2}+\ldots+\frac{1}{\zeta N-\lfloor\zeta N\rfloor+\lfloor\zeta N\rfloor} \\
& =\frac{1}{1+\lambda}+\frac{1}{2+\lambda}+\ldots+\frac{1}{(N-\lceil\zeta N\rceil)+\lambda} \\
& +\frac{1}{1+(1-\lambda)}+\frac{1}{2+(1-\lambda)}+\ldots+\frac{1}{\lfloor\zeta N\rfloor+(1-\lambda)} .
\end{aligned}
$$

Define

$$
S_{N-\lceil\zeta N\rceil}^{1}=\frac{1}{1+\lambda}+\frac{1}{2+\lambda}+\ldots+\frac{1}{(N-\lceil\zeta N\rceil)+\lambda}
$$

and

$$
S_{\lfloor\zeta N\rfloor}^{2}=+\frac{1}{1+(1-\lambda)}+\frac{1}{2+(1-\lambda)}+\ldots+\frac{1}{\lfloor\zeta N\rfloor+(1-\lambda)} .
$$

The series $S_{n}^{1}$ is a generalized harmonic series of length $n$. If we define $S_{n}^{0}=1+\frac{1}{2}+\ldots \frac{1}{n}$ as the standard harmonic series of length $n$, we see that $S_{N-\lceil\zeta N\rceil+1}^{0}-1<S_{N-\lceil\zeta N\rceil}^{1}<S_{N-\lceil\zeta N\rceil}^{0}$. For large $n$ we know that $S_{n}^{0} \rightarrow \gamma+\ln n$ where $\gamma$ is the Euler-Mascheroni constant $(\gamma \approx .577)$. Hence 
$\gamma+\ln \frac{N-\lceil\zeta N\rceil+1}{e}<S_{N-\lceil\zeta N\rceil}^{1}<\gamma+\ln (N-\lceil\zeta N\rceil)$. From a similar reasoning, $\gamma+\ln \frac{\lfloor\zeta N\rfloor+1}{e}<S_{\lfloor\zeta N\rfloor}^{2}<$ $\gamma+\ln (\lfloor\zeta N\rfloor)$. It follows that

$$
2 \gamma+\ln \frac{N-\lceil\zeta N\rceil+1}{e}+\ln \frac{\lfloor\zeta N\rfloor+1}{e}<\sum \frac{1}{|\zeta N-i|+1}<2 \gamma+\ln (N-\lceil\zeta N\rceil)+\ln (\lfloor\zeta N\rfloor) .
$$

Hence $\frac{1}{N} \sum \frac{1}{|\zeta N-i|+1} \rightarrow 0$ as $N \rightarrow+\infty$. As this hold for any $p_{k}$, it also holds for the sum so $\bar{w} \rightarrow 0$ as $N \rightarrow+\infty$. Moreover, it also holds for the sum weighted by $\nu_{k}$ so $\bar{r} \rightarrow 0$ as $N \rightarrow+\infty$.

2) The behavior of $\sum_{i=1}^{N} \sum_{k=1}^{K} \frac{i}{1+\left|p_{k}-i\right|}$ :

We proceed by splitting in the same manner, yielding

$$
\begin{aligned}
\sum \frac{i}{|p-i|+1} & =\frac{\lceil\zeta N\rceil}{\lceil\zeta N\rceil-\zeta N+1}+\frac{\lceil\zeta N\rceil+1}{\lceil\zeta N\rceil-\zeta N+2}+\ldots+\frac{N}{\lceil\zeta N\rceil-\zeta N+(N-\lceil\zeta N\rceil)} \\
& +\frac{\lfloor\zeta N\rfloor}{\zeta N-\lfloor\zeta N\rfloor+1}+\frac{\lfloor\zeta N\rfloor-1}{\zeta N-\lfloor\zeta N\rfloor+2}+\ldots+\frac{1}{\zeta N-\lfloor\zeta N\rfloor+\lfloor\zeta N\rfloor} .
\end{aligned}
$$

We have

$$
\begin{aligned}
& \frac{\lceil\zeta N\rceil+1}{\lceil\zeta N\rceil-\zeta N+1}+\frac{\lceil\zeta N\rceil+2}{\lceil\zeta N\rceil-\zeta N+2}+\ldots+\frac{N}{\lceil\zeta N\rceil-\zeta N+(N-\lceil\zeta N\rceil)} \\
& =(\lceil\zeta N\rceil-1)\left(\frac{1}{\lceil\zeta N\rceil-\zeta N+1}+\frac{1}{\lceil\zeta N\rceil-\zeta N+2}+\ldots+\frac{1}{\lceil\zeta N\rceil-\zeta N+(N-\lceil\zeta N\rceil)}\right) \\
& +\frac{1}{\lceil\zeta N\rceil-\zeta N+1}+\frac{2}{\lceil\zeta N\rceil-\zeta N+2}+\ldots+\frac{N-\lceil\zeta N\rceil}{\lceil\zeta N\rceil-\zeta N+(N-\lceil\zeta N\rceil)} \\
& =(\lceil\zeta N\rceil-1) S_{N}^{1}+T_{N-\lceil\zeta N\rceil}^{1},
\end{aligned}
$$

where the series

$$
T_{n}^{1}=\frac{1}{1+\lambda}+\frac{2}{2+\lambda}+\ldots+\frac{n}{n+\lambda} .
$$

We know that

$$
\frac{n}{1+\lambda}<T_{n}^{1}<n
$$


Similarly,

$$
\begin{aligned}
\frac{\lfloor\zeta N\rfloor}{\zeta N-\lfloor\zeta N\rfloor+1}+\frac{\lfloor\zeta N\rfloor-1}{\zeta N-\lfloor\zeta N\rfloor+2}+\ldots+\frac{1}{\zeta N-\lfloor\zeta N\rfloor+\lfloor\zeta N\rfloor} \\
=(\lfloor\zeta N\rfloor+1)\left(\frac{1}{\zeta N-\lfloor\zeta N\rfloor+1}+\frac{1}{\zeta N-\lfloor\zeta N\rfloor+2}+\ldots+\frac{1}{\zeta N-\lfloor\zeta N\rfloor+\lfloor\zeta N\rfloor}\right) \\
-\left(\frac{1}{\zeta N-\lfloor\zeta N\rfloor+1}+\frac{2}{\zeta N-\lfloor\zeta N\rfloor+2}+\ldots+\frac{\lfloor\zeta N\rfloor}{\zeta N-\lfloor\zeta N\rfloor+\lfloor\zeta N\rfloor}\right) \\
=(\lfloor\zeta N\rfloor+1) S_{N}^{2}-T_{\lfloor\zeta N\rfloor}^{2}
\end{aligned}
$$

where the series

$$
T_{n}^{2}=\frac{1}{1+(1-\lambda)}+\frac{2}{2+(1-\lambda)}+\ldots+\frac{n}{n+(1-\lambda)}
$$

We know that

$$
\frac{n}{2-\lambda}<T_{n}^{2}<n
$$

It follows that

$$
\frac{1}{N} \sum \frac{i}{|p-i|+1}=\frac{(\lceil\zeta N\rceil-1) S_{N-\lceil\zeta N\rceil}^{1}+(\lfloor\zeta N\rfloor+1) S_{\lfloor\zeta N\rfloor}^{2}+T_{N-\lceil\zeta N\rceil}^{1}-T_{\lfloor\zeta N\rfloor}^{2}}{N}
$$

Hence

$$
\begin{aligned}
\frac{1}{N} \sum\left(\frac{1}{|p-i|+1}-\bar{w}\right) i & =\left(\frac{\lceil\zeta N\rceil-1}{N}-\frac{N+1}{2 N}\right) S_{N-\lceil\zeta N\rceil}^{1} \\
& +\left(\frac{(\lfloor\zeta N\rfloor+1)}{N}-\frac{N+1}{2 N}\right) S_{\lfloor\zeta N\rfloor}^{2}+\frac{T_{N-\lceil\zeta N\rceil}^{1}-T_{\lfloor\zeta N\rfloor}^{2}}{N}
\end{aligned}
$$

When $N \rightarrow+\infty$, we see that the two first parentheses converge to $\zeta-\frac{1}{2}$ and the last fraction to a constant $\Xi \in\left(-\frac{\lambda}{1+\lambda}, \frac{1-\lambda}{2-\lambda}\right)$. Hence the expression converges to a log function, so $w_{k}=$ $\frac{1}{N} \sum\left(\frac{1}{|p-i|+1}-\bar{w}\right) i \rightarrow+\infty$ as $N \rightarrow+\infty$.

3) Behavior of the numerator:

Then the full numerator can be written as $\sum_{k=1}^{K} w_{k} \nu_{k}$. Define the set $K_{+}=\left\{k: \nu_{k}>0\right\}$ and 
$K_{-}=\left\{k: \nu_{k}<0\right\}$. Now as $N \rightarrow+\infty$, the numerator converges to

$$
\frac{1}{N} \sum_{k \in K_{+}} \nu_{k} w_{k}+\frac{1}{N} \sum_{k \in K_{-}} \nu_{k} w_{k}
$$

At least one of the sums diverge. If only one diverge, the numerator converges to either $+\infty$ (only the first diverge) or $-\infty$ (only the second diverge). Furthermore, if both diverge we have $\operatorname{Pr}\left(\left|\sum_{k=1}^{K} w_{k} \nu_{k}\right| \rightarrow+\infty\right)=1$. To see this, notice that for a given realization of $\left\{\nu_{2}, \ldots, \nu_{K}\right\}$ (and the $p_{k} \mathrm{~s}$ if they are taken as random), there is only one value of $\nu_{1}$ that assures convergence. The probability of this realization is zero as the $\nu_{k} \mathrm{~s}$ have continuous distributions. Hence with probability 1 the numerator of (4) diverges. 


\section{B.2. Proof of convergence of the denominator in (4)}

Proof. We want to study the behavior of $\sqrt{\frac{1}{N^{2}} \sum_{i=1}^{N}\left(\sum_{k=1}^{K} \frac{1}{\left|p_{k}-i\right|+1}-\bar{w}\right)^{2}}=: \sqrt{\frac{1}{N^{2}} A_{N}}$. We have $A_{N}=\sum_{i=1}^{N}\left(\sum_{k=1}^{K} \frac{1}{\left|p_{k}-i\right|+1}\right)^{2}-N \bar{w}^{2}$. We know from the proof in Appendix B.1 that $\bar{w}$ converges to a $\log$ function so $\frac{\bar{w}^{2}}{N} \rightarrow 0$ as $N \rightarrow \infty$.

We first study the behavior of $\sum_{i=1}^{N}\left(\frac{1}{\left|p_{k}-i\right|+1}\right)^{2}$ for any choice of $k$. We want to show that as $N \rightarrow \infty$, it converges to a finite positive value $Q_{k \infty}$. As for the proof in B.1, define $\lambda=\lceil\zeta N\rceil-\zeta N$ (so $1-\lambda=\zeta N-\lfloor\zeta N\rfloor)$. Then we have

$$
\begin{aligned}
\sum\left(\frac{1}{|\zeta N-i|+1}\right)^{2} & =\left(\frac{1}{\lceil\zeta N\rceil-\zeta N+1}\right)^{2}+\left(\frac{1}{\lceil\zeta N\rceil-\zeta N+2}\right)^{2}+\ldots \\
& +\left(\frac{1}{\lceil\zeta N\rceil-\zeta N+(N-\lceil\zeta N\rceil)}\right)^{2} \\
& +\left(\frac{1}{\zeta N-\lfloor\zeta N\rfloor+1}\right)^{2}+\left(\frac{1}{\zeta N-\lfloor\zeta N\rfloor+2}\right)^{2}+\ldots \\
& =\left(\frac{1}{1+\lambda}\right)^{2}+\left(\frac{1}{2+\lambda}\right)^{2}+\ldots+\left(\frac{1}{(N N-\lceil\zeta N\rfloor+\lfloor\zeta N\rfloor}\right)^{2} \\
& +\left(\frac{1}{1+(1-\lambda)}\right)^{2}+\left(\frac{1}{2+(1-\lambda)}\right)^{2}+\ldots+\left(\frac{1}{\lfloor\zeta N\rfloor+(1-\lambda)}\right)^{2}
\end{aligned}
$$

Define the series

$$
Q_{N-\lceil\zeta N\rceil}^{1}=\left(\frac{1}{1+\lambda}\right)^{2}+\left(\frac{1}{2+\lambda}\right)^{2}+\ldots+\left(\frac{1}{(N-\lceil\zeta N\rceil)+\lambda}\right)^{2}
$$

and

$$
Q_{\lfloor\zeta N\rfloor}^{2}=\left(\frac{1}{1+(1-\lambda)}\right)^{2}+\left(\frac{1}{2+(1-\lambda)}\right)^{2}+\ldots+\left(\frac{1}{\lfloor\zeta N\rfloor+(1-\lambda)}\right)^{2}
$$

and define the sum of the the reciprocals of the squares of natural numbers $Q_{n}^{0}=\sum_{i=1}^{n}\left(\frac{1}{i}\right)^{2}$. Then we see that $Q_{1+N-\lceil\zeta N\rceil}^{0}-1 \leq Q_{N-\lceil\zeta N\rceil}^{1} \leq Q_{N-\lceil\zeta N\rceil}^{0}$ and $Q_{1+\lfloor\zeta N\rfloor}^{0}-1 \leq Q_{\lfloor\zeta N\rfloor}^{2} \leq Q_{\lfloor\zeta N\rfloor}^{0}$. Hence for given $\zeta$ we get $\lim _{N \rightarrow \infty} \sum\left(\frac{1}{|\zeta N-i|+1}\right)^{2}=Q_{k \infty}$. Moreover, as $\lim _{n \rightarrow \infty} Q_{n}^{0}=\frac{\pi^{2}}{6}$, we have 
$\frac{\pi^{2}}{3}-2 \leq Q_{k \infty} \leq \frac{\pi^{2}}{3}$.

Consider next the cross terms $\sum_{i=1}^{N} \frac{1}{\left|p_{k}-i\right|+1} \frac{1}{\left|p_{k}^{\prime}-i\right|+1}=: B_{k k^{\prime} N}$ for any choices of $k \neq k^{\prime}$. As $\frac{1}{\left|p_{k}-i\right|+1}>0$ for any $p_{k} \in[1, N]$, we have $B_{k k^{\prime} N}>0$. Moreover, it follows from the Cauchy-Schwarz inequality that $B_{k k^{\prime} N} \leq \sqrt{Q_{k \infty} Q_{k^{\prime} \infty}} \leq \frac{\pi^{2}}{3}$.

Hence as $N \rightarrow \infty$, we have $A_{N} \rightarrow \sum_{k=1}^{K} \sum_{k^{\prime}=1}^{K} \sqrt{Q_{k \infty} Q_{k^{\prime} \infty}}$, so $0<A_{n} \leq K^{2} \frac{\pi^{2}}{6}$. Hence if $\frac{K}{N} \rightarrow \kappa \in \mathbb{R}^{+}$, the denominator in (4) converges to a non-zero constant whereas if $\frac{K}{N} \rightarrow 0$, the denominator in (4) converges to 0 . 


\section{THE DATA}

The meteorological data used in the paper are created by the Norwegian Meteorological Institute (met.no). The data are based on daily observations of precipitation at all 421 measurement stations in Norway, and based on spatial interpolation using a residual kriging approach (Tveito \& Førland, 1999; Mohr, 2008). First, each observation is regressed on a number of geographic properties to separate between a deterministic and a stochastic part. The residuals are then interpolated using kriging and combined with deterministic parts to obtain a grid of $1 \times 1 \mathrm{~km}$ cells for Norway. As one would expect, average rainfall is larger along the west coast and in parts of the north.

To get municipal averages, I combine the data with GIS data on municipal boundaries to construct data on average precipitation by municipality for each election year. Municipal boundaries have changed over time, and GIS data on past municipal borders are essentially non-existent. To solve this I map municipalities that no longer exist into their current municipality and use weather data from the present day municipality.

Average precitipation values on election days are shown in Panel (a) of Appendix Figure 7. Panel (b) of Appendix Figure 7 show the average election day precipitation and turnout for the period 1971-2007. There are no clear geographical trends in average turnout.

My preferred measure is a dummy variable for substantial rain on election day, specified as above $1 / 10$ of an inch or $2.5 \mathrm{~mm}$. However, other cut off as well as a linear specification yield comparable results.

Data on electoral turnout taken from the recent collection of Norwegian municipal data made available by Fiva et al. (2012), originating from Statistics Norway and the Norwegian Social Science Data Services. Data from the ten municipal elections between 1971 and 2007 were used. The data on median gross household incomes was taken from Statistics Norway's StatBank. The sample covers all municipal medians for the years 1993-2012.

[Figure 7 about here.] 


\section{ADDITIONAL MONTE CARLO RESULTS}

[Table 5 about here.]

[Table 6 about here.]

[Table 7 about here.] 


\section{List of Figures}

1 Spurious t-values . . . . . . . . . . . . . . . . . . . . . . . . . 39

2 Distribution of the t-values . . . . . . . . . . . . . . . . . 40

3 Spatio-temporal patterns in turnout . . . . . . . . . . . . . . . . . 41

4 The stylized econometric model . . . . . . . . . . . . . . . . . . . . 42

5 The number of terms in the nonparametric trend model . . . . . . . . . . . . . . 43

6 Distribution of t-values controlling for spatio-temporal trends . . . . . . . . . . . . 44

7 Average rainfall . . . . . . . . . . . . . . . . . . . . . 45

8 Spurious t-values in regressions of income on rainfall . . . . . . . . . . . 54

9 Distribution of simulated t-values . . . . . . . . . . . . . . . 55

10 Distribution of estimated coefficients controlling for spatio-temporal trends . . . . 56 
Figure 1: Spurious t-values

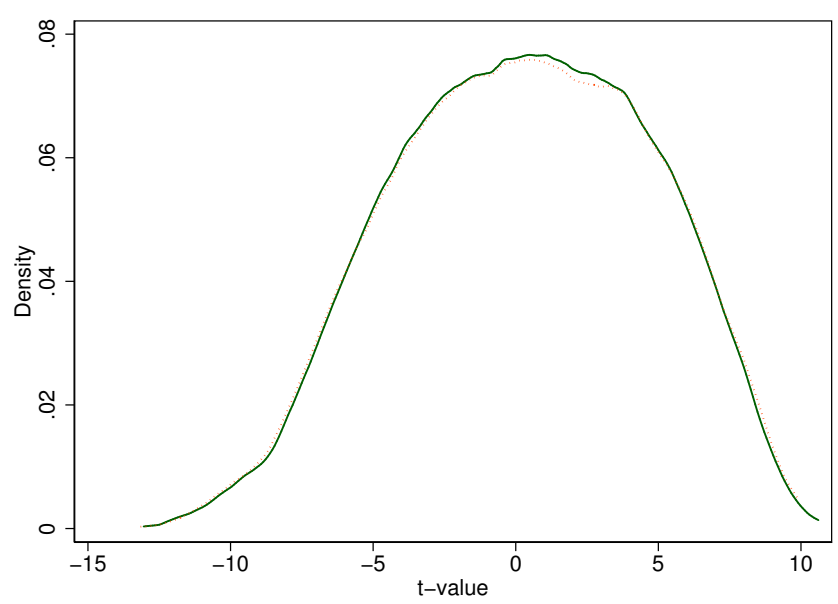

Notes: The graph shows the coefficient from two way fixed effects regression of electoral turnout on a dummy for substantial daily precipitation. The dotted orange line shows the distribution when controlling for real election day rainfall whereas the solid green line excludes this variable. Standard errors are clustered at the municipal level. Precipitation for 600 days before to 600 days after election day employed, but data from $+/-10$ days are excluded. 
Figure 2: Distribution of the t-values

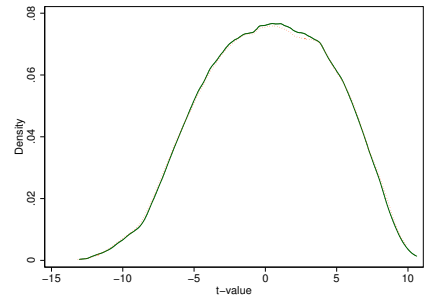

(a) No normalization

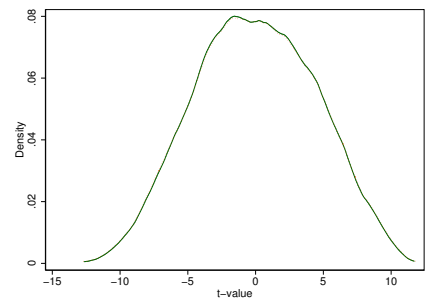

(b) Dummy for substantial(c) Dummy for positive rain rain

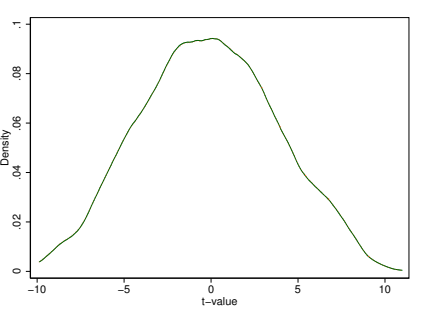

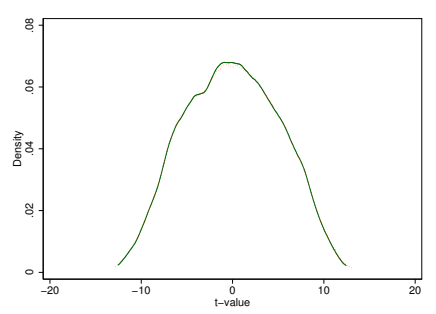

(d) Measured as ranks

Notes: The graph shows the distribution of the t-values when regressing municipal turnout on daily precipitation for 600 days before and after election day. The dotted orange line shows the distribution when controlling for real election day rainfall whereas the solid green line excludes this variable. The 10 days before and after the actual election day are omitted. Panel (a) shows results from regressing levels on levels. Panel (b) shows the regression of turnout on a dummy for more than $25 \mathrm{~mm}$ rain while Panel (c) employs a dummy for any rain. Panel (d) shows results from a regression where the rank of turnout is measured on the rank of rain, i.e. both variables are uniform on the unit interval. 
Figure 3: Spatio-temporal patterns in turnout

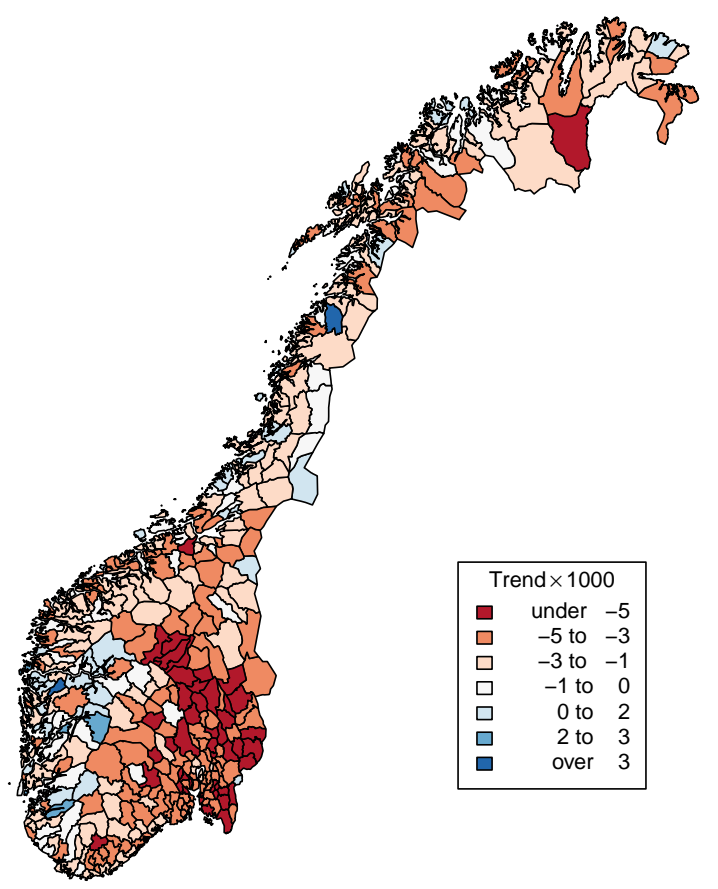

(a) Trends by municipality

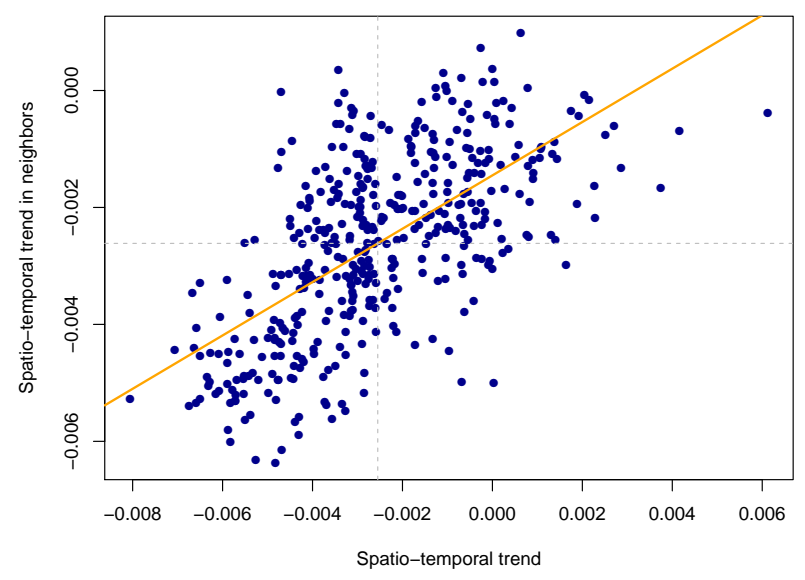

(b) Trends in neighboring municipalities

Notes: The figure shows municipality specific coefficients $\delta_{i}$ from the regression (1). Red areas are strong negative, blue areas strong positive. 
Figure 4: The stylized econometric model

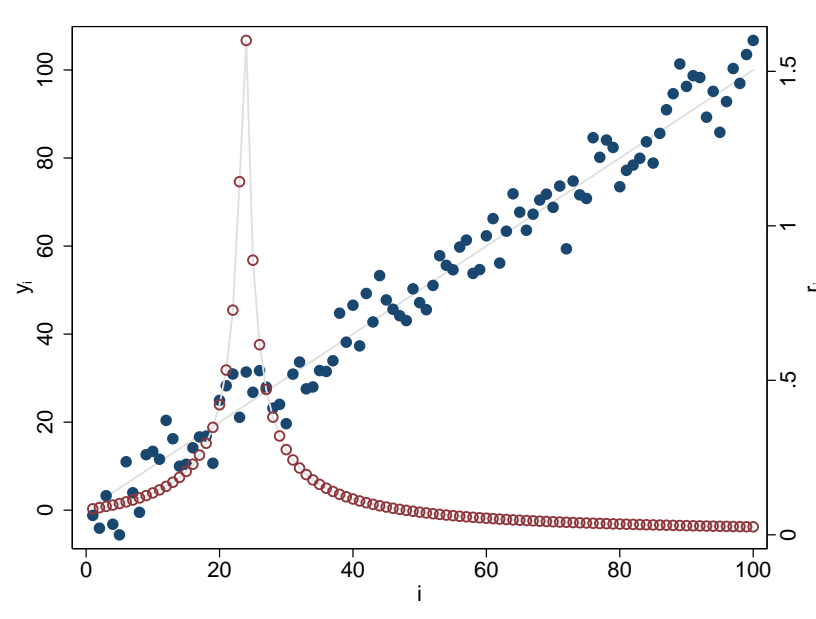

(a) The set up

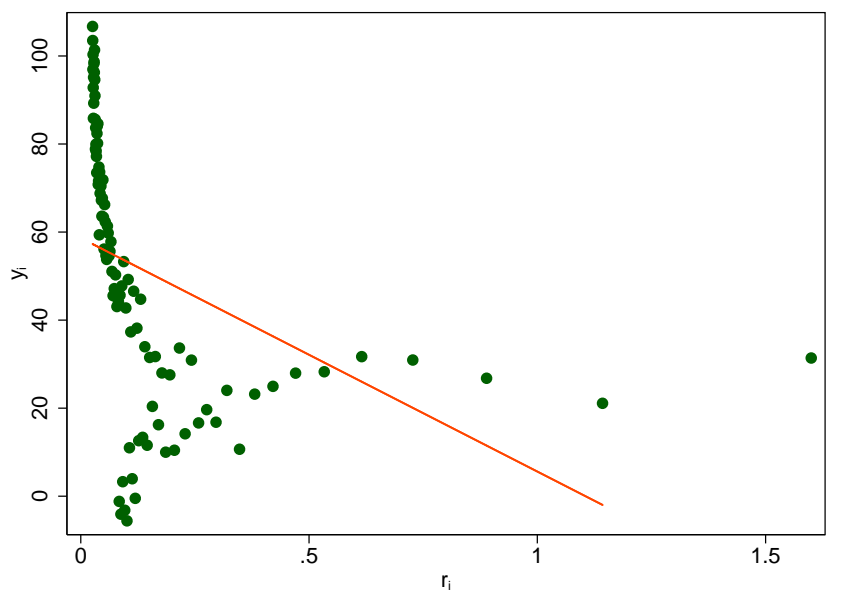

(b) The relationship

Notes: Panel (a) shows the simulated $y_{i}$ and $r_{i}$ against the observation number $i$. Panel (b) shows a scatter plot of $y_{i}$ versus $r_{i}$ as well as a linear fit of the data. Data are simulated for $\beta=0$. 
Figure 5: The number of terms in the nonparametric trend model

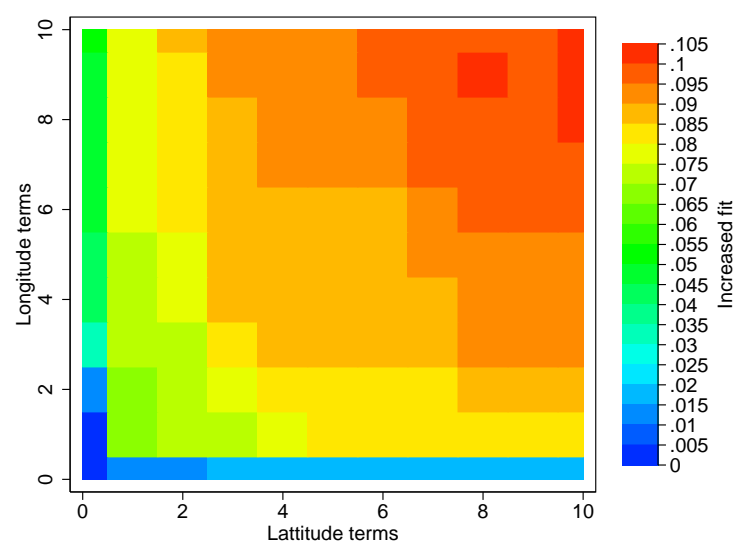

(a) Model fit and number of longiude and latitude terms

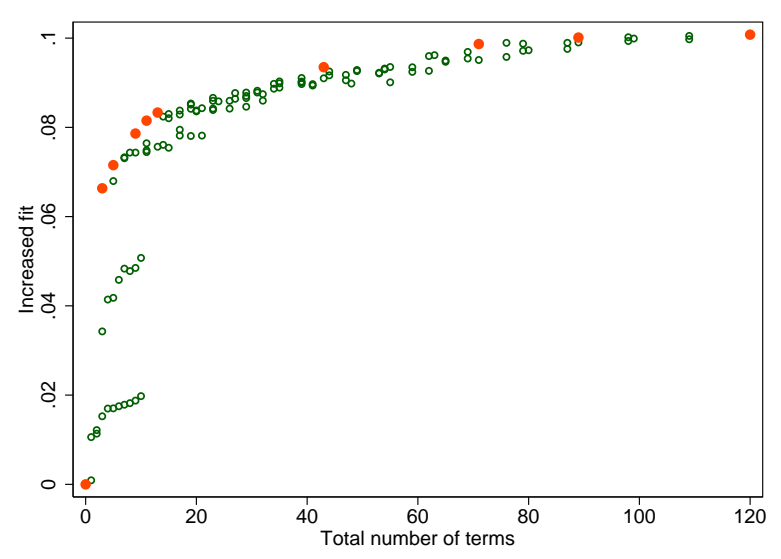

(b) Model fit and total number of terms

Notes: Panel (a) shows model fit as a function of the number of terms in the longitudinal and latitudinal polynomials, whereas Panel (b) shows fit as a function of the total number of terms included in the tensor product. Approximation is with tensor products of Legendre polynomials of varying degrees. In Panel (b), combinations that belong to the convex hull are shown with solid orange dots and other combinations with hollow green dots. 
Figure 6: Distribution of t-values controlling for spatio-temporal trends

(a) No normalization

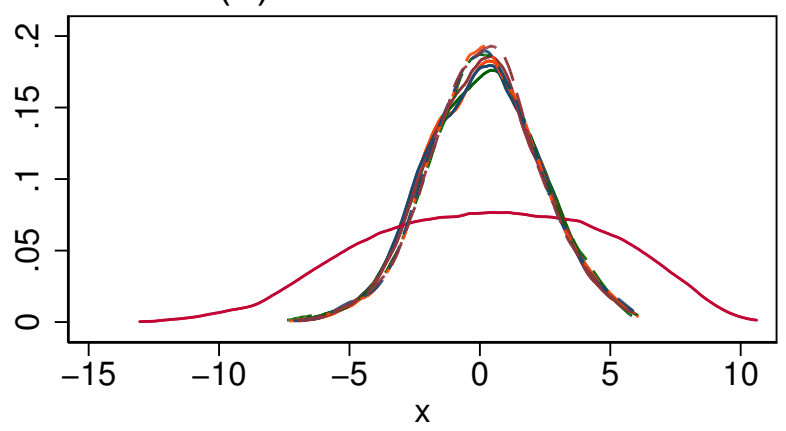

(c) Dummy for substantial rain

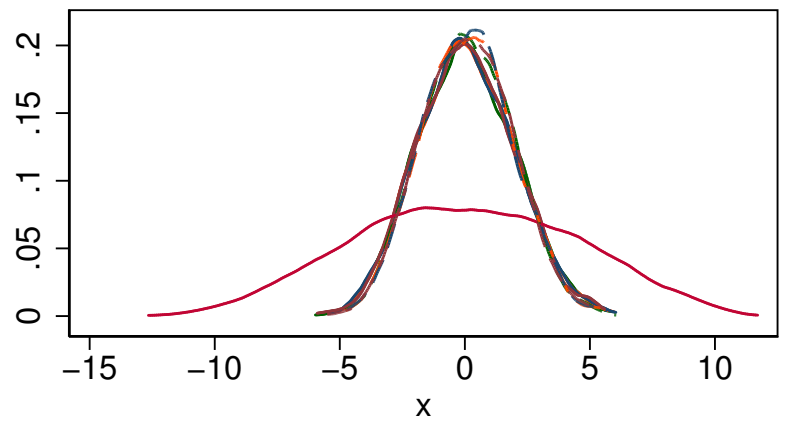

(b) Dummy for positive rain

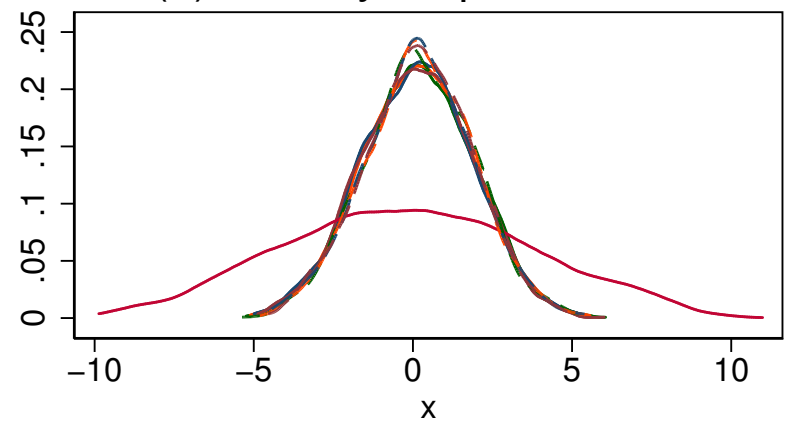

(d) Measured as ranks

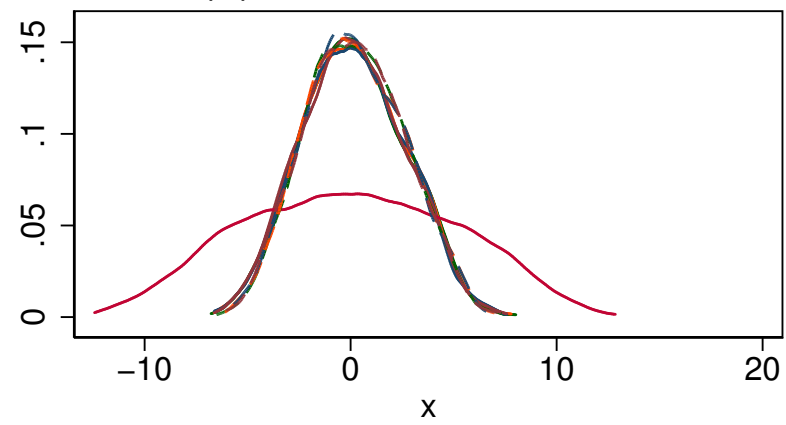

Notes:The graph shows the distribution of the t-values when regressing municipal turnout on daily precipitation for 600 days before and after election day. The 10 days before and after the actual election day are omitted. Panel (a) shows results from regressing levels on levels. Panel (b) shows the regression of turnout on a dummy for more than $2.5 \mathrm{~mm}$ rain while Panel (c) employs a dummy for any rain. Panel (d) shows results from a regression where the rank of turnout is measured on the rank of rain, i.e. both variables are uniform on the unit interval.

Spatio-temporal trends are controlled for using tensor products of Legendre polynomials with $1 \times 6$, $3 \times 10$, and $7 \times 8$ terms as well as regional trends. The graph also includes the t-values obtained without spatio-temporal trends. Linear temporal trends are shown in solid lines and quadratic linear trends in dashed lines. 
Figure 7: Average rainfall

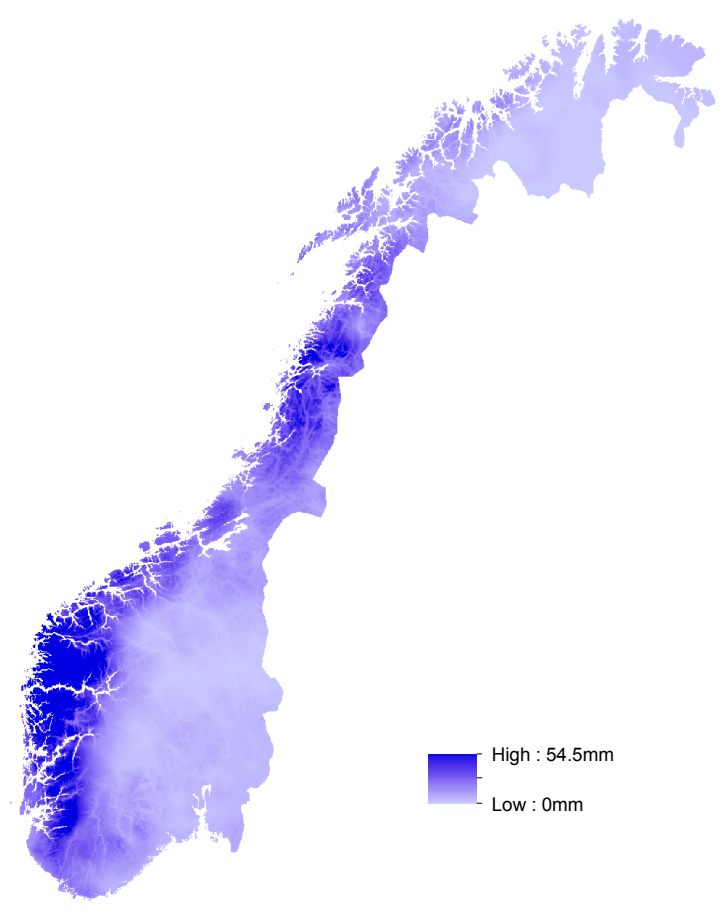

Notes: The graph shows average precipitation on election day, averaged over the elections 1971200\%. Dark colors indicate high levels of precipitation. 


\section{List of Tables}

1 Monte Carlo simulations based on actual rainfall . . . . . . . . . . . . . . . . . . 47

2 A Monte Carlo analysis of the simple model . . . . . . . . . . . . . . . . . 48

3 The effect of precipitation on turnout . . . . . . . . . . . . . . . . 49

4 Empirical work including rainfall in some top journals . . . . . . . . . . . . . 50

5 A Monte Carlo analysis of the spatial model . . . . . . . . . . . . . . . . 51

$6 \quad$ A Monte Carlo analysis of the panel data model . . . . . . . . . . . . . 52

$7 \quad$ A Monte Carlo analysis of a model with autoregressive spatial correlation . . . . . . 53

8 The effect of precipitation on turnout - additional specifications . . . . . . . . . 57 
Table 1: Monte Carlo simulations based on actual rainfall

\begin{tabular}{lcccc}
\hline & Mean & Std. dev. & Skewness & Share rejected \\
\hline 1) No clustering & 0.38 & 9.13 & 0.43 & 0.84 \\
2) Clustered on region & 0.25 & 3.41 & 1.20 & 0.59 \\
3) Conley standard errors & 0.18 & 3.15 & 0.62 & 0.59 \\
4) Random municipality & -0.04 & 1.00 & 0.17 & 0.05 \\
5) Panel & -0.62 & 7.96 & 0.12 & 0.81 \\
\hline
\end{tabular}

Notes: The Table shows the results of Monte Carlo analyses simulating data as in (2) with $\epsilon_{i} \sim$ $N(0,1)$ and 1000 replications. All regressions are cross sectional analyses except the last row which is based on a two way fixed effects panel data estimator. The cut offs for the Conley standard errors were chosen as the standard deviation of the coordinates (longitude \pm 3.5 , longitude \pm 5 degrees). 
Table 2: A Monte Carlo analysis of the simple model

\begin{tabular}{lccccccc}
\hline & \multicolumn{7}{c}{$\mathrm{K}$} \\
$\mathrm{nyyyyyyy} \mathrm{N}$ & 1 & 2 & 5 & 10 & 100 & $\mathrm{~N}$ & $2 \mathrm{~N}$ \\
\hline \multirow{2}{*}{10} & 0.59 & 0.57 & 0.51 & 0.49 & 0.49 & 0.49 & 0.51 \\
& 2.6 & 2.6 & 2.4 & 2.4 & 2.4 & 2.3 & 2.3 \\
50 & 0.77 & 0.67 & 0.64 & 0.66 & 0.62 & 0.62 & 0.63 \\
& 3.9 & 3.5 & 3.4 & 3.4 & 3.3 & 3.3 & 3.5 \\
100 & 0.79 & 0.74 & 0.69 & 0.68 & 0.67 & 0.67 & 0.66 \\
& 4.3 & 4 & 3.8 & 3.8 & 3.8 & 3.8 & 3.7 \\
1000 & 0.86 & 0.82 & 0.82 & 0.80 & 0.78 & 0.75 & 0.82 \\
& 6.2 & 6.1 & 6 & 5.7 & 5.6 & 5.4 & 5.9 \\
10000 & 0.90 & 0.88 & 0.86 & 0.87 & 0.83 & 0.86 & 0.83 \\
& 8.8 & 8.5 & 8.2 & 8.3 & 7.9 & 7.7 & 7.9 \\
\hline
\end{tabular}

Notes:The table shows the fraction of cases where a t-test of $\beta=0$ is rejected at the $5 \%$ level (first line) and the average of the absolute value of the associated t-value (second line). The true model is $\beta=0, \tau=1, \epsilon_{i} \sim N(0,1)$, and for each $k, \nu_{k} \sim N(0,1)$ and the position $p_{k} \sim U(0, N)$. Each model is replicated 1000 times. 
Table 3: The effect of precipitation on turnout

\begin{tabular}{lccccc}
\hline & \multicolumn{2}{c}{ Without trend } & & \multicolumn{2}{c}{ With trend } \\
\cline { 2 - 3 } \cline { 5 - 6 } & $(1)$ & $(2)$ & & $(3)$ & $(4)$ \\
\hline Rain (in cm) & -0.000339 & $0.00134^{* *}$ & & $0.00299^{* * *}$ & $0.00283^{* * *}$ \\
& $(-0.50)$ & $(2.46)$ & & $(5.34)$ & $(5.29)$ \\
Rain $\times$ Year & & $0.00185^{* * *}$ & & -0.000356 \\
& & $(6.96)$ & & $(-1.56)$ \\
\hline Mean dep. var & 0.681 & 0.681 & 0.681 & 0.681 \\
Obs & 4417 & 4417 & & 4417 & 4417 \\
$\mathrm{R}^{2}$ & 0.612 & 0.624 & 0.698 & 0.698 \\
\hline
\end{tabular}

Notes: Outcome variable is municipal electoral turnout. All specifications include municipal and year fixed effects. Specifications (3) and (4) also include the tensor product of Legendre polynomials with $1 \times 6$ terms to control for spatio-temporal trends. Standard errors are clustered at the municipality level (using the 2010 municipal structure).

t-values in parentheses, and *, **, and ${ }^{* * *}$ denotes significant at the 10\%, 5\%, and $1 \%$ levels. 
Table 4: Empirical work including rainfall in some top journals

\begin{tabular}{|c|c|c|c|c|c|c|c|}
\hline Author & Title & Year & Refrence & Weather variables & Spatial resolution & $\begin{array}{l}\text { Fixed effects and } \\
\text { controls }\end{array}$ & Clustering \\
\hline Robert Jensen & $\begin{array}{l}\text { Agricultural Volatility and Investments in Children } \\
\text { The Razor's Edge: Distortions and Incremental Reform in the People's }\end{array}$ & 2000 & AER P\&P 90(2): $399-404$ & Monthly rainfall & Region & & \\
\hline Alwyn Young & $\begin{array}{l}\text { Republic of China } \\
\text { Work Environment and Individual Background: Explaining Regional }\end{array}$ & 2000 & QJE 115(4): 1091-1135 & Monthly rainfall & Province & Province & \\
\hline Andrea Ichino and Giovanni Maggi & Shirking Differentials in a Large Italian Firm & 2000 & QJE 115(3): 1057-1090 & Yearly rainfall and temperature & Province & & Province \\
\hline Stefan Dercon and Pramila Krishna & $\begin{array}{l}\text { In Sickness and in Health: Risk Sharing within Households in Rural Ethiopia } \\
\text { Transport Costs and the Geography of Arbitrage in Eighteenth-Century }\end{array}$ & 2000 & JPE 108(4): 688-727 & Annual rainfall & Village & & \\
\hline Carol H. Shiue & $\begin{array}{l}\text { China } \\
\text { The Political Economy of Government Responsiveness: Theory and }\end{array}$ & 2002 & AER 92(5): 1406-1419 & Annual aridity index & Prefecture & & \\
\hline $\begin{array}{l}\text { Timothy Besley and Robin Burgess } \\
\text { Abhijit V. Baneriee, Paul J. Gertler }\end{array}$ & Evidence from India & 2002 & QJE 117(4): 1415-1451 & Annual rainfall & States & States & \\
\hline and Maitreesh Ghatak & Empowerment and Efficiency: Tenancy Reform in West Bengal & 2002 & JPE 110(2): 239-280 & $\begin{array}{l}\text { Annual rainfall } \\
\text { Average annual rainfall, average January }\end{array}$ & District & District & \\
\hline Dora L. Costa and Matthew E. Kahn & $\begin{array}{l}\text { The Rising Price of Nonmarket Goods } \\
\text { Networks in the Modern Economy: Mexican Migrants in the U. S. Labor }\end{array}$ & 2003 & AER P\&P 93(2): 227-232 & and July temperature & Metropolitan area & & Metropolitan area \\
\hline $\begin{array}{l}\text { Kaivan Munshi } \\
\text { Andrew D. Foster and Mark R. }\end{array}$ & Market & 2003 & QJE 118(2): 549-599 & Annual rainfall & Community & Individual & Community-year \\
\hline Rosenzweig & Economic Growth and the Rise of Forests & 2003 & OJE 118(2): 601-637 & Annual rainfall & Village & Village & Village \\
\hline $\begin{array}{l}\text { Stephen Coate and Michael Conlin } \\
\text { Edward Miguel, Shanker Satyanath }\end{array}$ & A Group Rule: Utilitarian Approach to Voter Turnout: Theory and Evidence & 2004 & AER 94(5): 1476-1504 & Daily rainfall and snowfall & County & Country FE and time & \\
\hline $\begin{array}{l}\text { and Ernest Sergenti } \\
\text { Zeynep K. Hansen and Gary D. }\end{array}$ & Economic Shocks and Civil Conflict: An Instrumental Variables Approach & 2004 & JPE 112(4): 725-753 & Monthly rainfall & Country & trend & Country \\
\hline Libecap & $\begin{array}{l}\text { Small Farms, Externalities, and the Dust Bowl of the } 1930 \text { s } \\
\text { History, Institutions, and Economic Performance: The Legacy of Colonial }\end{array}$ & 2004 & JPE 112(3): $665-694$ & Annual rainfall & County & State & State \\
\hline Abhijit Banerjee and Lakshmi Iyer & Land TenureSystems in India & 2005 & AER 95(4): $1190-1213$ & $\begin{array}{l}\text { Mean annual rainfall } \\
\text { Hourly rainfall, daily snowfall, } \min / \max \end{array}$ & Spatial cross-section & Region $\mathrm{FE}$ & Region \\
\hline $\begin{array}{l}\text { Henry S. Farber } \\
\text { Wolfram Schlenker, W. Michael }\end{array}$ & $\begin{array}{l}\text { Is Tomorrow Another Day? The Labor Supply of New York City Cabdrivers } \\
\text { Will U.S. Agriculture Really Beneffit from Global Warming? Accounting for }\end{array}$ & 2005 & JPE 113(1): 46-82 & temperature & New York City & Individual & Driver shift \\
\hline $\begin{array}{l}\text { Hanemann and Anthony C. Fisher } \\
\text { Edward L. Glaeser and Joseph }\end{array}$ & Irrigation inthe Hedonic Approach & 2005 & AER 95(1): 395-406 & Monthly rainfall & County & & \\
\hline Gyourko & $\begin{array}{l}\text { Urban Decline and Durable Housing } \\
\text { Selling Labor Low: Wage Responses to Productivity Shocks in Developing }\end{array}$ & 2005 & JPE 113(2): :345-375 & Annual rainfall and temperature & City & & \\
\hline $\begin{array}{l}\text { Seema Jayachandran } \\
\text { Aaron S. Edlin and Pinar }\end{array}$ & Countries & 2006 & JPE 114(3): 538-575 & Annual rainfall & District & District & Region-year \\
\hline $\begin{array}{l}\text { Karaca-Mandic } \\
\text { Michael Conlin, Ted O'Donoghue and }\end{array}$ & The Accident Externality from Driving & 2006 & JPE 114(5): 931-955 & Annual rainfall and snowfall & State & $\begin{array}{l}\text { State } \\
\text { Month-region, year- }\end{array}$ & \\
\hline Timothy J. Vogelsang & Projection Bias in Catalog Orders & 2007 & AER 97(4): 1217-1249 & Daily temperature and snowfall & Zip code & region & Household \\
\hline $\begin{array}{l}\text { Esther Duflo and Rohini Pande } \\
\text { Henry S. Farber }\end{array}$ & $\begin{array}{l}\text { Dams } \\
\text { Reference-Dependent Preferences and Labor Supply: The Case of New } \\
\text { York City TaxiDrivers }\end{array}$ & 2007 & QJE 122(2): 601-646 & $\begin{array}{l}\text { Annual rainfall } \\
\text { Hourly rinfall, daily snowfall, } \min / \max \\
\text { temperature }\end{array}$ & New York City & District & $\begin{array}{l}\text { None, autocorrelation } \\
\text { robust method }\end{array}$ \\
\hline Nathan Nunn & The Long-Term Effects of Africa's Slave Trades & 2008 & OJE 123(1): $139-176$ & Average monthly temperature and rainfall & Country & Colonizer & \\
\hline Gustavo J. Bobonis & $\begin{array}{l}\text { Is the Allocation of Resources within the Household Efficient? New } \\
\text { Evidence from a Randomized Experiment } \\
\text { Under the Weather: Health, Schooling, and Economic Consequences of }\end{array}$ & 2009 & JPE 117(3): 453-503 & 6 month average & Village-period & $\begin{array}{l}\text { Household FE } \\
\text { District-season } \mathrm{FE}\end{array}$ & Village \\
\hline $\begin{array}{l}\text { Sharon Maccini and Dean Yang } \\
\text { Douglas Almond, Lena Edlund and }\end{array}$ & $\begin{array}{l}\text { Early-life Rainfall } \\
\text { Chernobyl's Subclinical Legacy: Prenatal Exposure to Radioactive Fallout }\end{array}$ & 2009 & AER 99(3): 1006-1026 & Monthly rainfall & District & and trend & Province \\
\hline Mấrten Palme & and School Outcomes in Sweden & 2009 & QJE 124(4): 1729-1772 & Daily rainfall & County & Sibling & County \\
\hline $\begin{array}{l}\text { Gordon Dahl and Stefano Dellavigna } \\
\text { Joseph H. Davis, Christopher Hanes }\end{array}$ & Does Movie Violence Increase Violent Crime? & 2009 & QJE 124(2): 677-734 & Daily weather conditions & National & & \\
\hline and Paul W. Rhode & $\begin{array}{l}\text { Harvests and Business Cycles in Nineteenth-Century America } \\
\text { Can Openness Mitigate the Effects of Weather Shocks? Evidence from }\end{array}$ & 2009 & QJE 124(4): 1675-1727 & Monthly rainfall and temperature & Cotton belt & & \\
\hline $\begin{array}{l}\text { Robin Burgess and Dave Donaldson } \\
\text { Jean-Michel Chevet, Sébastien }\end{array}$ & $\begin{array}{l}\text { India's Famine Era } \\
\text { Climate, Grapevine Phenology, Wine Production, and Prices: Pauillac (1800- }\end{array}$ & 2010 & AER P\&P 100(2): 449-453 & $\begin{array}{l}\text { Annual rainfall } \\
\text { Daily rainfall and temperatures }\end{array}$ & District-year & 2-way FE & District \\
\hline $\begin{array}{l}\text { Lecocq and Michael Visser } \\
\text { John S. Felkner and Robert M. }\end{array}$ & 2009) & 2011 & AER P\&P 101(3): 142-146 & (aggregated) & Time series & & Various spatial \\
\hline Townsend & $\begin{array}{l}\text { The Geographic Concentration of Enterprise in Developing Countries } \\
\text { Quitters Never Win: The (Adverse) Incentive Effects of Competing with }\end{array}$ & 2011 & QJE 126(4): 2005-2061 & Annual rainfall variation & Village & & techniques \\
\hline Jennifer Brown & Superstars & 2011 & JPE 119(5): 982-1013 & Daily temperature, wind, rainfall & Golf course & Course*player & Player*year \\
\hline Lori Beaman and Jeremy Magruder & Who Gets the Job Referral? Evidence from a Social Networks Experiment & 2012 & AER 102(7): 3574-3593 & Daily rainfall & Time series for study site & None & None \\
\hline $\begin{array}{l}\text { Andreas Madestam, Daniel Shoag, } \\
\text { Stan Veuger, David Yanagizawa-Drott }\end{array}$ & $\begin{array}{l}\text { Do Political Protests Matter? Evidence from the Tea Party Movement } \\
\text { Risk Sharing and Transactions Costs: Evidence from Kenya's Mobile Money }\end{array}$ & 2013 & QJE 128(4): 1633-1685 & Daily rainfall & $\begin{array}{l}\text { Country/congressional } \\
\text { district }\end{array}$ & Region & State, Conley \\
\hline $\begin{array}{l}\text { William Jack and Tavneet Suri } \\
\text { Mark R. Rosenzweig and Christopher }\end{array}$ & $\begin{array}{l}\text { Revolution } \\
\text { Rainfall Forecasts, Weather, and Wages over the Agricultural Production }\end{array}$ & 2014 & AER 104(1): $183-223$ & Season rainfall & Location & Location & \\
\hline $\begin{array}{l}\text { Udry } \\
\text { Raymond Guiteras, Amir lina, and A. }\end{array}$ & $\begin{array}{l}\text { Cycle } \\
\text { Satellites, Self-reports, and Submersion: }\end{array}$ & 2014 & AER P\&P 104(5): 278-283 & Monthly rainfall & Village & Village & \\
\hline $\begin{array}{l}\text { Raymond Guiteras, Amir Jina, and A. } \\
\text { Mushfiq Mobarak }\end{array}$ & $\begin{array}{l}\text { Satellites, Self-reports, and submersion: } \\
\text { Exposure to Floods in Bangladesh }\end{array}$ & 2015 & AER P\&P 105(5): 232-236 & Monthly rainfall & Distict & & \\
\hline $\begin{array}{l}\text { Solomon M. Hsiang and Kyle C. Meng } \\
\text { Meghan R. Busse, Devin G. Pope, }\end{array}$ & : Tropical Economics & 2015 & AER P\&P 105(5): $257-261$ & Average temperature and rainfall & Country & Country & Conley \\
\hline $\begin{array}{l}\text { Jaren C. Pope, Jorge Silva-Risso } \\
\text { Henry s. Farber }\end{array}$ & $\begin{array}{l}\text { The Psychological Effect of Weather on Car Purchases } \\
\text { Why you Can't Find a Taxi in the Rain and Other Labor Supply Lessons from } \\
\text { Cab Drivers }\end{array}$ & $\begin{array}{l}2015 \\
2015\end{array}$ & OJE 130(1): 371-414 & $\begin{array}{l}\text { Daily weather conditions } \\
\text { Hourly rainfall }\end{array}$ & $\begin{array}{l}\text { Designated market area } \\
\text { Central Park }\end{array}$ & $\mathrm{DMA}^{*}$ week of year & $\begin{array}{l}\text { DMA*day } \\
\text { Driver }\end{array}$ \\
\hline Peter Koudijs & $\begin{array}{l}\text { Those Who Know Most: Insider Trading in Eighteenth-Century Amsterdam } \\
\text { Economic Activity and the Spread of Vira Diseases: Evidence from High }\end{array}$ & 2015 & JPE 123(6): 1356-1409 & Daily wind, rainfall, temperature & Amsterdam, London & & \\
\hline $\begin{array}{l}\text { Jérôme Adda } \\
\text { Alan Barreca, Karen Clay, Olivier }\end{array}$ & Frequency Data & 2016 & QJE 131(2): 891-941 & Weekly rainfall and temperatures & Region & Region & Region \\
\hline $\begin{array}{l}\text { Joseph S. Shapiro } \\
\text { Joyce J. Chen, Valerie Mueller, }\end{array}$ & $\begin{array}{l}\text { Adapting to Cilmate Change: Inh Remarkable Decinene in the US } \\
\text { Temperature-Mortality Relationship over the Twentieth Century }\end{array}$ & 2016 & JPE 124(1): 105-159 & Daily rainfall and temperature & Stat & State ${ }^{*}$ month & State \\
\hline $\begin{array}{l}\text { Yuanyuan Jia, and Steven Kuo-Hsin } \\
\text { Tseng }\end{array}$ & $\begin{array}{l}\text { Validating Migration Responses to Flooding Using Satellite and } \\
\text { Vital Registration Data } \\
\text { Drought of Opportunities: Contemporaneous and Long-Term Impacts of }\end{array}$ & 2017 & AER P\&P 107(5): 441-445 & Monthly rainfall & Subdistrict-month & $\begin{array}{l}\text { Year } \mathrm{FE} \text {, historical } \\
\text { climate }\end{array}$ & Primary sampling unit \\
\hline $\begin{array}{l}\text { Manisha Shah and Bryce Millett } \\
\text { Steinberg }\end{array}$ & $\begin{array}{l}\text { Rainfall Shocks } \\
\text { on Human Capital }\end{array}$ & 2017 & JPE 125(2): 527-561 & Monthly rainfall & District & District & District \\
\hline
\end{tabular}

Notes: The table shows the articles found in the survey of the American Economic Review, the Quarterly Journal of Economics, and the Journal of Political Economy 2000-2017. The search was a search for the presence of the work "rainfall" somewhere in the article text. A few articles discussing rainfall theoretically, as well as work on rainfall index insurance are not included on the list. 
Table 5: A Monte Carlo analysis of the spatial model

\begin{tabular}{lccccccc}
\hline & \multicolumn{7}{c}{$\mathrm{K}$} \\
\cline { 2 - 7 } $\mathrm{N}$ & 1 & 2 & 5 & 10 & 100 & $\mathrm{~N}$ & $2 \mathrm{~N}$ \\
\hline 9 & 0.37 & 0.36 & 0.31 & 0.32 & 0.30 & 0.29 & 0.25 \\
& 1.76 & 1.71 & 1.59 & 1.59 & 1.56 & 1.53 & 1.42 \\
25 & 0.57 & 0.58 & 0.55 & 0.54 & 0.54 & 0.54 & 0.51 \\
& 2.84 & 2.78 & 2.57 & 2.52 & 2.44 & 2.49 & 2.43 \\
49 & 0.65 & 0.66 & 0.66 & 0.65 & 0.63 & 0.66 & 0.64 \\
& 3.8 & 3.84 & 3.59 & 3.47 & 3.28 & 3.41 & 3.35 \\
100 & 0.73 & 0.76 & 0.73 & 0.74 & 0.72 & 0.71 & 0.75 \\
& 5.21 & 5.12 & 4.79 & 4.87 & 4.61 & 4.6 & 4.64 \\
400 & 0.85 & 0.85 & 0.84 & 0.85 & 0.85 & 0.85 & 0.83 \\
& 9.15 & 8.98 & 8.5 & 8.6 & 8.12 & 8.56 & 7.79 \\
1024 & 0.88 & 0.90 & 0.90 & 0.91 & 0.89 & 0.89 & 0.90 \\
& 13.1 & 12.9 & 12.7 & 12.7 & 12.3 & 11.7 & 12.2 \\
10000 & 0.95 & 0.96 & 0.96 & 0.94 & 0.96 & 0.95 & 0.96 \\
& 31.5 & 31.6 & 31.5 & 30.3 & 29.8 & 31 & 31.4 \\
\hline
\end{tabular}

Notes:The table shows the fraction of cases where a t-test of $\beta=0$ is rejected at the $5 \%$ level (first line) and the average of the absolute value of the associated t-value (second line). The true model is $z_{i}=\alpha+\beta \sum r_{i}+\tau\left(x_{i}+y_{i}\right)+\epsilon_{i}$ with $\beta=0, \tau=1, \epsilon_{i} \sim N(0,1)$, and for each $k, \nu_{k} \sim N(0,1)$ and the position $p_{k} \sim U([0, N] \times[0, N])$. Each model is replicated 1000 times. 


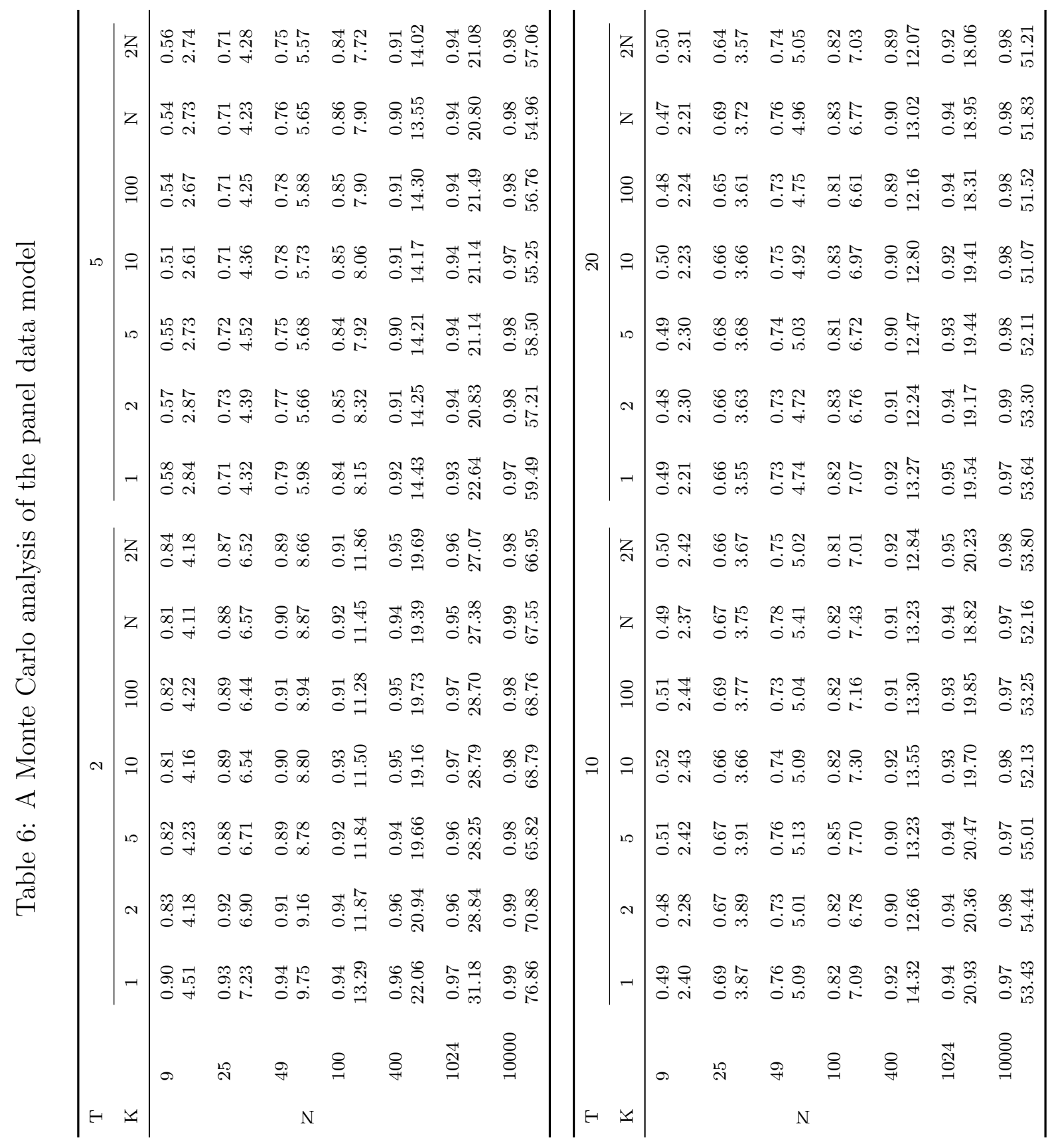

$\frac{2}{3} \div$

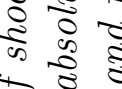

$\circ$

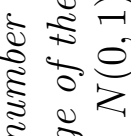

उ

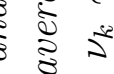
z

i

कू हु

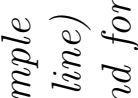

है के

स造宗

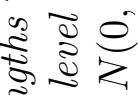

हू de?

च 20

离

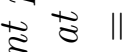

ปั ฐ

S.

$\therefore$ \& 11

इ क्ष

20.2

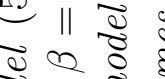

จ

है

원워

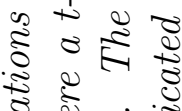

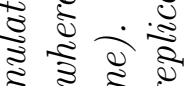

है के है

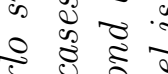

है $+8 \frac{8}{8}$

2 요

हิ

골

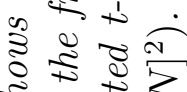

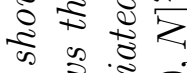

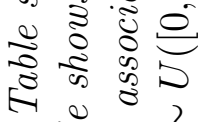

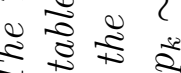

$-10 \%$

نु

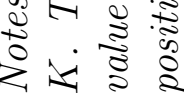


Table 7: A Monte Carlo analysis of a model with autoregressive spatial correlation

\begin{tabular}{|c|c|c|c|c|c|c|c|c|c|c|c|c|c|c|c|}
\hline \multirow{2}{*}{$\begin{array}{l}\rho \\
\mathrm{K}\end{array}$} & & \multicolumn{7}{|c|}{.5} & \multicolumn{7}{|c|}{.75} \\
\hline & & 1 & 2 & 5 & 10 & 100 & $\mathrm{~N}$ & $2 \mathrm{~N}$ & 1 & 2 & 5 & 10 & 100 & $\mathrm{~N}$ & $2 \mathrm{~N}$ \\
\hline \multirow{10}{*}{ 乙 } & 10 & 0.19 & 0.19 & 0.17 & 0.18 & 0.17 & 0.19 & 0.18 & 0.25 & 0.26 & 0.24 & 0.22 & 0.25 & 0.24 & 0.22 \\
\hline & & 1.2 & 1.2 & 1.1 & 1.2 & 1.2 & 1.2 & 1.2 & 1.5 & 1.4 & 1.4 & 1.3 & 1.4 & 1.4 & 1.3 \\
\hline & 50 & 0.24 & 0.22 & 0.21 & 0.22 & 0.22 & 0.22 & 0.22 & 0.36 & 0.35 & 0.35 & 0.36 & 0.36 & 0.35 & 0.31 \\
\hline & & 1.3 & 1.3 & 1.2 & 1.3 & 1.2 & 1.3 & 1.3 & 1.8 & 1.7 & 1.7 & 1.7 & 1.7 & 1.7 & 1.6 \\
\hline & 100 & 0.24 & 0.22 & 0.23 & 0.19 & 0.24 & 0.22 & 0.21 & 0.38 & 0.42 & 0.39 & 0.38 & 0.40 & 0.34 & 0.38 \\
\hline & & 1.3 & 1.3 & 1.3 & 1.2 & 1.3 & 1.3 & 1.3 & 1.8 & 1.8 & 1.8 & 1.8 & 1.8 & 1.7 & 1.8 \\
\hline & 1000 & 0.25 & 0.20 & 0.23 & 0.23 & 0.26 & 0.19 & 0.26 & 0.44 & 0.39 & 0.39 & 0.39 & 0.39 & 0.39 & 0.42 \\
\hline & & 1.3 & 1.3 & 1.3 & 1.3 & 1.4 & 1.2 & 1.4 & 1.9 & 1.8 & 1.8 & 1.8 & 1.9 & 1.8 & 1.9 \\
\hline & 10000 & 0.24 & 0.22 & 0.25 & 0.22 & 0.22 & 0.24 & 0.22 & 0.41 & 0.41 & 0.41 & 0.40 & 0.40 & 0.40 & 0.39 \\
\hline & & 1.3 & 1.3 & 1.3 & 1.3 & 1.3 & 1.3 & 1.3 & 1.9 & 1.9 & 1.9 & 1.9 & 1.9 & 1.9 & 1.8 \\
\hline \multirow{2}{*}{\multicolumn{2}{|c|}{$\begin{array}{l}\rho \\
\mathrm{K}\end{array}$}} & \multicolumn{7}{|c|}{.95} & \multicolumn{7}{|c|}{1} \\
\hline & & 1 & 2 & 5 & 10 & 100 & $\mathrm{~N}$ & $2 \mathrm{~N}$ & 1 & 2 & 5 & 10 & 100 & $\mathrm{~N}$ & $2 \mathrm{~N}$ \\
\hline \multirow{10}{*}{ 乙 } & 10 & 0.40 & 0.33 & 0.33 & 0.29 & 0.31 & 0.34 & 0.29 & 0.39 & 0.39 & 0.34 & 0.34 & 0.31 & 0.34 & 0.34 \\
\hline & & 1.8 & 1.7 & 1.6 & 1.6 & 1.6 & 1.7 & 1.6 & 1.9 & 1.8 & 1.8 & 1.7 & 1.6 & 1.7 & 1.7 \\
\hline & 50 & 0.57 & 0.50 & 0.49 & 0.51 & 0.47 & 0.49 & 0.49 & 0.59 & 0.55 & 0.52 & 0.55 & 0.54 & 0.52 & 0.53 \\
\hline & & 2.6 & 2.4 & 2.3 & 2.4 & 2.3 & 2.3 & 2.3 & 2.8 & 2.7 & 2.5 & 2.6 & 2.7 & 2.6 & 2.6 \\
\hline & 100 & 0.56 & 0.58 & 0.56 & 0.56 & 0.53 & 0.53 & 0.52 & 0.68 & 0.64 & 0.60 & 0.59 & 0.59 & 0.61 & 0.58 \\
\hline & & 2.7 & 2.8 & 2.7 & 2.8 & 2.6 & 2.5 & 2.6 & 3.4 & 3.2 & 3.1 & 3.1 & 3 & 3.1 & 3 \\
\hline & 1000 & 0.60 & 0.61 & 0.63 & 0.61 & 0.64 & 0.63 & 0.59 & 0.81 & 0.79 & 0.77 & 0.75 & 0.75 & 0.74 & 0.75 \\
\hline & & 3.1 & 3.3 & 3.2 & 3.1 & 3.3 & 3.2 & 3 & 5.5 & 5.1 & 5.1 & 5 & 4.9 & 5 & 5 \\
\hline & 10000 & 0.65 & 0.64 & 0.64 & 0.65 & 0.64 & 0.61 & 0.63 & 0.86 & 0.86 & 0.80 & 0.85 & 0.82 & 0.83 & 0.83 \\
\hline & & 3.2 & 3.3 & 3.3 & 3.4 & 3.4 & 3.2 & 3.3 & 7.8 & 7.5 & 7.3 & 7.1 & 7.3 & 7.2 & 7.4 \\
\hline
\end{tabular}

Notes: The Table shows Monte Carlo simulations of model (6) for different autoregressive coefficients $\rho$, sample sizes $N$, and number of shocks $K$. The table shows the fraction of cases where a t-test of $\beta=0$ is rejected at the $5 \%$ level (first line) and the average of the absolute value of the associated t-value (second line). The true model is $\beta=0, \tau=1, \epsilon_{i} \sim N(0,1)$, and for each $k$, $\nu_{k} \sim N(0,1)$ and the position $p_{k} \sim U\left([0, N]^{2}\right)$. Each model is replicated 1000 times. 


\section{E. ADDITIONAL GRAPHS AND TABLES}

Figure 8: Spurious t-values in regressions of income on rainfall

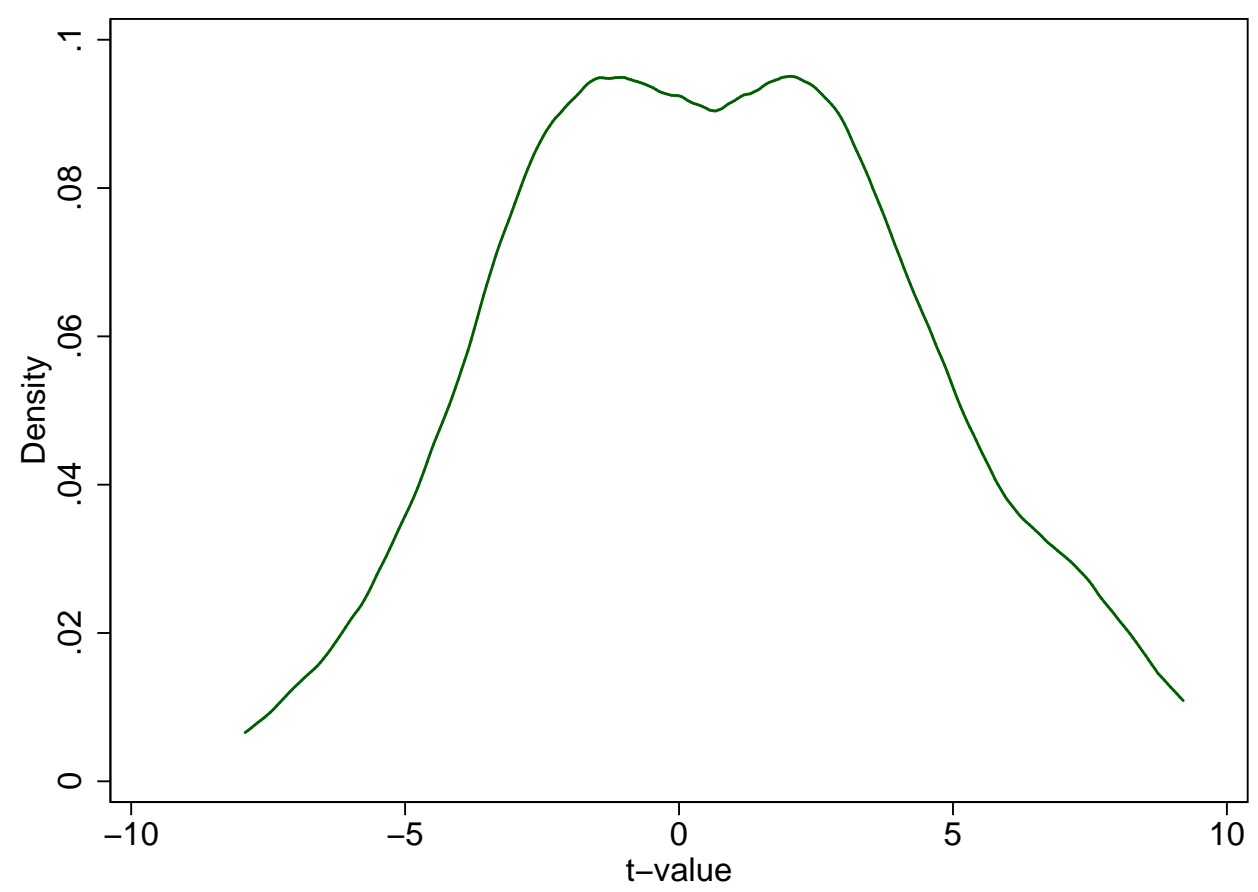

Notes: The graph shows the coefficient from two way fixed effects regression of municipal median gross income on a dummy for substantial daily precipitation. Standard errors are clustered at the municipal level. Data for the 365 days of the year are used. 
Figure 9: Distribution of simulated t-values
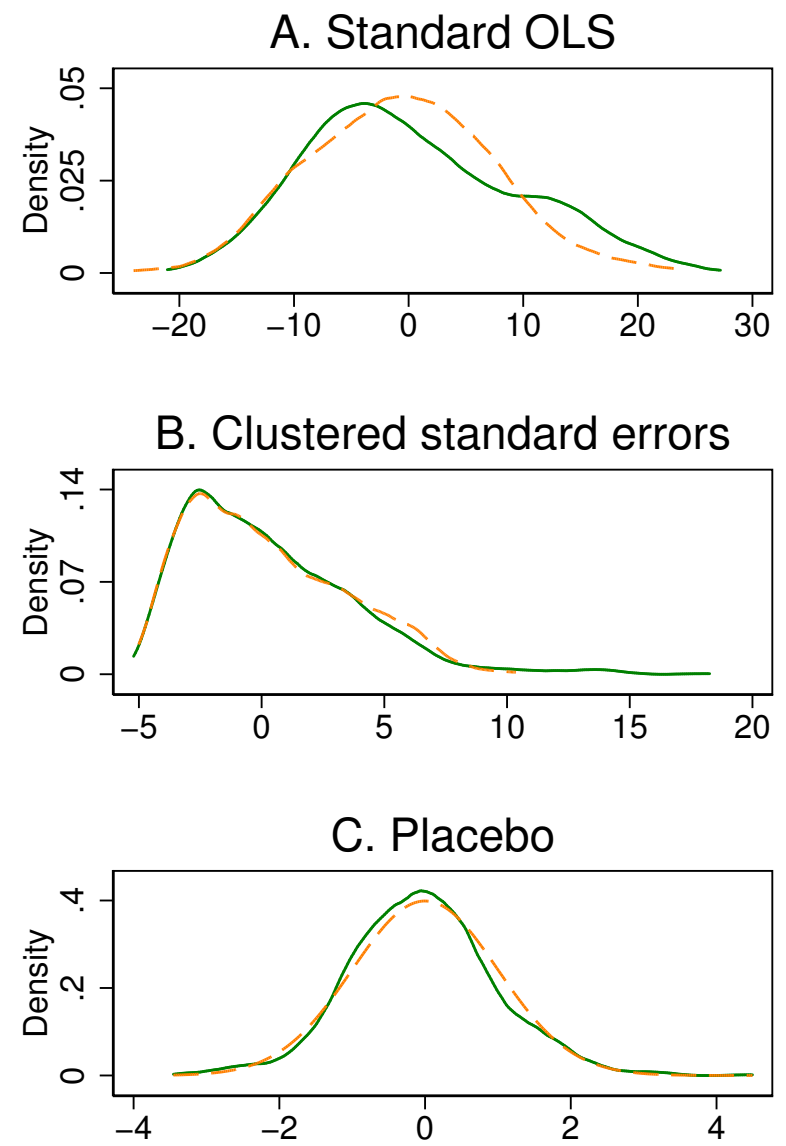

Notes: The graphs show the distribution of t-values obtained from the Monte Carlo analyses of spatial trends on actual rainfall. Panel A shows the distribution of the t-values without clustering in the cross sectional setting (solid green lines) and with a panel (dashed orange). Panel B shows the values in the cross section clustering at the regional level (solid green) and using Conley standard errors (dashed orange). The cut offs for the Conley standard errors were chosen as the standard deviation of the coordinates (longitude \pm 3.5 , longitude \pm 5 degrees). Panel $C$ shows the distribution of the placebo with randomly chosen municipalities (solid green) and the standard normal distribution (dotted orange). 
Figure 10: Distribution of estimated coefficients controlling for spatio-temporal trends

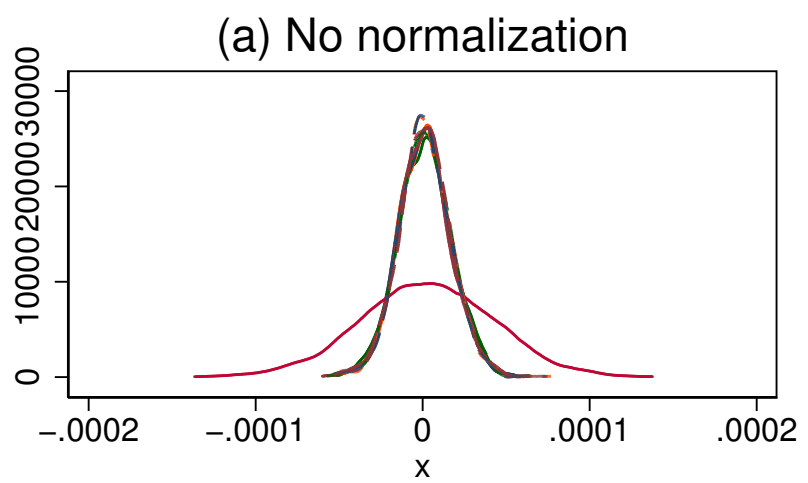

(b) Dummy for positive rain

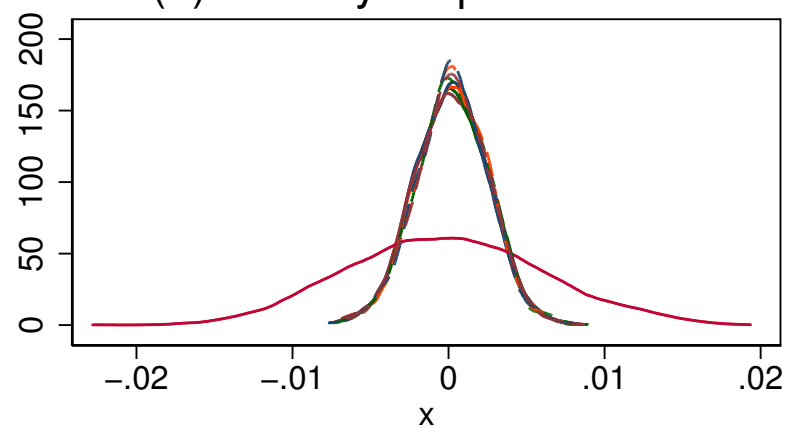

(c) Dummy for substantial rain

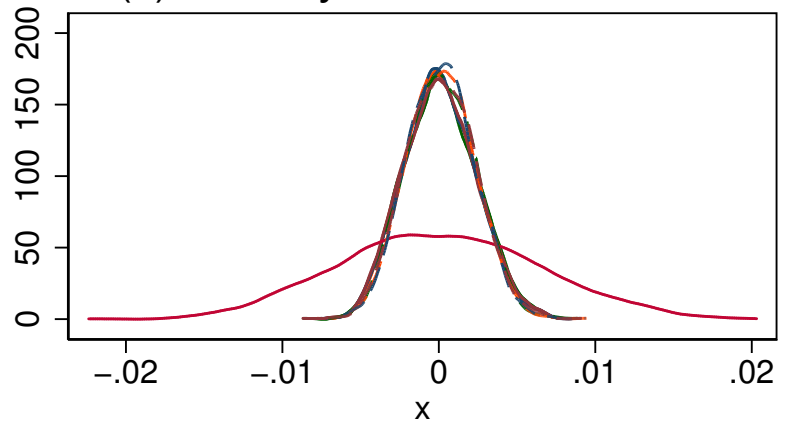

(d) Measured as ranks

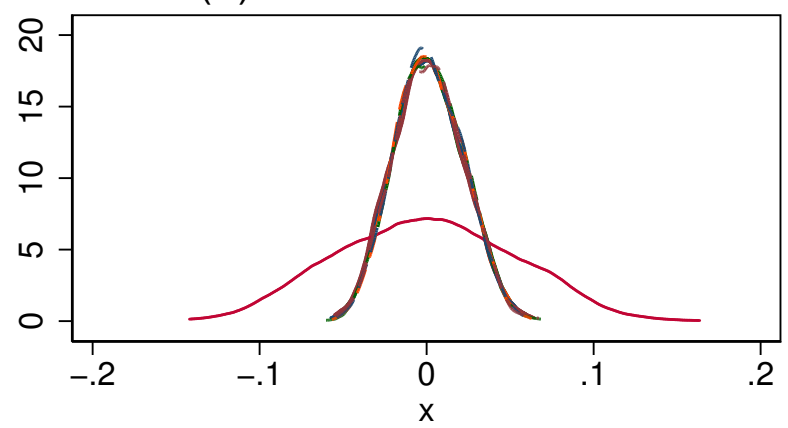

Notes:The graph shows the distribution of the estimated coefficients when regressing municipal turnout on daily precipitation for 600 days before and after election day. The 10 days before and after the actual election day are omitted. Panel (a) shows results from regressing levels on levels. Panel (b) shows the regression of turnout on a dummy for more than $25 \mathrm{~mm}$ rain while Panel (c) employs a dummy for any rain. Panel (d) shows results from a regression where the rank of turnout is measured on the rank of rain, i.e. both variables are uniform on the unit interval.

Spatio-temporal trends are controlled for using tensor products of Legendre polynomials with $1 \times 6$, $3 \times 10$, and $7 \times 8$ terms as well as regional trends. Linear temporal trends are shown in solid lines and quadratic linear trends in dashed lines. 
Table 8: The effect of precipitation on turnout - additional specifications

\section{Panel A: Estimation without spatio-temporal trends}

\begin{tabular}{|c|c|c|c|c|c|c|}
\hline & (1) & $(2)$ & $(3)$ & (4) & (5) & (6) \\
\hline Rain (in cm) & $\begin{array}{c}-0.000339 \\
(-0.50)\end{array}$ & & & $\begin{array}{c}-0.000579 \\
(-0.84)\end{array}$ & $\begin{array}{c}-0.000436 \\
(-0.51)\end{array}$ & $\begin{array}{c}0.00134^{* *} \\
(2.46)\end{array}$ \\
\hline Rain positive & & $\begin{array}{c}0.00546^{* * *} \\
(3.55)\end{array}$ & & $\begin{array}{c}0.00572^{* * *} \\
(3.57)\end{array}$ & & \\
\hline Rain above $2.5 \mathrm{~mm}$ & & & $\begin{array}{c}-0.000143 \\
(-0.12)\end{array}$ & & $\begin{array}{c}0.000396 \\
(0.26)\end{array}$ & \\
\hline Rain $\times$ Year & & & & & & $\begin{array}{c}0.00185^{* * *} \\
\quad(6.96)\end{array}$ \\
\hline Mean dep. var & 0.681 & 0.681 & 0.681 & 0.681 & 0.681 & 0.681 \\
\hline Obs & 4417 & 4417 & 4417 & 4417 & 4417 & 4417 \\
\hline $\mathrm{R}^{2}$ & 0.612 & 0.613 & 0.612 & 0.613 & 0.612 & 0.624 \\
\hline
\end{tabular}

Panel B: Estimation with spatio-temporal trends

\begin{tabular}{|c|c|c|c|c|c|c|}
\hline & (1) & $(2)$ & $(3)$ & (4) & (5) & (6) \\
\hline Rain (in cm) & $\begin{array}{c}0.00299^{* * *} \\
\quad(5.34)\end{array}$ & & & $\begin{array}{c}0.00270^{* * *} \\
\quad(4.81)\end{array}$ & $\begin{array}{c}0.00244^{* * *} \\
\quad(3.58)\end{array}$ & $\begin{array}{c}0.00283^{* * *} \\
\quad(5.29)\end{array}$ \\
\hline Rain positive & & $\begin{array}{c}0.00742^{* * *} \\
\quad(5.31)\end{array}$ & & $\begin{array}{c}0.00618^{* * *} \\
(4.41)\end{array}$ & & \\
\hline Rain above $2.5 \mathrm{~mm}$ & & & $\begin{array}{c}0.00511^{* * * *} \\
\quad(4.94)\end{array}$ & & $\begin{array}{c}0.00215^{*} \\
(1.69)\end{array}$ & \\
\hline Rain $\times$ Year & & & & & & $\begin{array}{c}-0.000356 \\
(-1.56)\end{array}$ \\
\hline Mean dep. var & 0.681 & 0.681 & 0.681 & 0.681 & 0.681 & 0.681 \\
\hline Obs & 4417 & 4417 & 4417 & 4417 & 4417 & 4417 \\
\hline $\mathrm{R}^{2}$ & 0.698 & 0.697 & 0.697 & 0.699 & 0.698 & 0.698 \\
\hline
\end{tabular}

Notes: Outcome variable is municipal electoral turnout. All specifications include municipal and year fixed effects. All specificationsin Panel B also include the tensor product of Legendre polynomials with $1 \times 6$ terms to control for spatio-temporal trends. Standard errors are clustered at the municipality level (using the 2010 municipal structure).

t-values in parentheses, and *, **, and *** denotes significant at the 10\%, 5\%, and 1\% levels. 